\title{
New Resistorless and Electronically Tunable Realization of Dual-Output VM All-Pass Filter Using VDIBA
}

\author{
NORBERT HERENCSAR, SHAHRAM MINAEI, JAROSLAV KOTON, \\ ERKAN YUCE, KAMIL VRBA
}

\author{
Citation: Analog Integrated Circuits and Signal Processing, vol. 74, iss. 1, pp. 141-154 \\ ISSN: 0925-1030 (Print) \\ ISSN: 1573-1979 (Online) \\ DOI: http://dx.doi.org/10.1007/s10470-012-9936-2
}

Accepted manuscript

The final publication is available at Springer via http://dx.doi.org/10.1007/s10470-012-9936-2 


\title{
New Resistorless and Electronically Tunable Realization of Dual-Output VM All-Pass Filter Using VDIBA
}

\author{
Norbert Herencsar ${ }^{1 凶}$, Shahram Minaei ${ }^{2}$, Jaroslav Koton ${ }^{1}$, Erkan Yuce ${ }^{3}$, and Kamil Vrba ${ }^{1}$ \\ ${ }^{1}$ Brno University of Technology, Dept. of Telecommunications, Purkynova 118, 61200 Brno, Czech \\ Republic \\ E-mail: herencsn@feec.vutbr.cz, koton@feec.vutbr.cz,vrbak@feec.vutbr.cz \\ ${ }^{2}$ Dogus University, Dept. of Electronics and Communications Engineering, 34722 Kadikoy-Istanbul, Turkey \\ E-mail: sminaei@dogus.edu.tr \\ ${ }^{3}$ Pamukkale University, Dept. of Electrical and Electronics Engineering, 20070 Kinikli-Denizli, Turkey, \\ Turkey \\ E-mail: erkanyuce@yahoo.com \\ ${ }^{\otimes}$ Corresponding author
}

\begin{abstract}
In this paper, a new active element called voltage differencing inverting buffered amplifier (VDIBA) is presented. Using single VDIBA and a capacitor, a new resistorless voltage-mode (VM) firstorder all-pass filter (APF) is proposed, which provides both inverting and non-inverting outputs at the same configuration simultaneously. The pole frequency of the filter can be electronically controlled by means of bias current of the internal transconductance. No component-matching conditions are required and it has low sensitivity. In addition, the parasitic and loading effects are also investigated. By connecting two newly introduced APFs in open loop a novel second-order APF is proposed. As another application, the proposed VM APF is connected in cascade to a lossy integrator in a closed loop to design a four-phase quadrature oscillator. The theoretical results are verified by SPICE simulations using TSMC $0.18 \mu \mathrm{m}$ level-7 CMOS process parameters with $\pm 0.9 \mathrm{~V}$ supply voltages. Moreover, the behavior of the proposed VM APF was also experimentally measured using commercially available integrated circuit OPA860 by Texas Instruments.
\end{abstract}

Keywords Analog signal processing; all-pass filter; electronically tunable circuit; four-phase quadrature oscillator; loading effect; resistorless filter; voltagemode; voltage differencing inverting buffered amplifier (VDIBA)

\section{Introduction}

All-pass filters are used to correct the phase shifts caused by analog filtering operations without changing the amplitude of the applied signal. In the literature, although many first-order voltage-mode (VM) all-pass filters (APFs) were proposed (e.g. [1]-[23] and references cited therein), only circuits in [3]-[23] are resistorless i.e. no external resistor is required and electronically tunable simultaneously. Table 1 summarizes the advantages and disadvantages of previously reported VM APFs in [1]-[23]. It is important to mention that we do not rule out the importance of the discussion on all the given criterions in the Table 1, however, in this part we concentrate on comparison of each circuit only regarding their tunability feature. In general, the tunability feature of circuits is solved in four different ways. After the current-controlled conveyor (CCCII) was introduced [24], a new period has been opened with respect to electronic tunability in the analog filter design. Here the intrinsic input resistance of the CCCII and other versatile analog building blocks (ABBs) is controlled via an external current or voltage, as shown in [3][11]. Similarly, the output resistance control of the CMOS inverting amplifier is demonstrated in [12]. Another technique is given in [13]-[16], where the appropriate resistor is replaced by MOSFET-based voltage-controlled resistor. In recently presented voltage differencing-differential input buffered amplifier (VD-DIBA)-based VM APF [17] and in other circuits [18]-[23] the tunability property of the operational transconductance amplifier (OTA) [25] is used to shift the phase response of the circuits. In fact, although the active element VD-DIBA, which belongs to the group of 'voltage differencing' elements [26], is new, it is composed of an OTA and a unity gain differential amplifier (UGDA), an interconnection that is done in [23] separately. 
Table 1. Comparison with previously published VM all-pass filters

\begin{tabular}{|c|c|c|c|c|c|c|c|c|c|}
\hline Ref. & $\begin{array}{l}\text { ABB } \\
\text { type }^{\#}\end{array}$ & $\begin{array}{l}\text { No. of } \\
\text { ABBs }\end{array}$ & $\begin{array}{l}\text { No. of } \\
\text { transistors }\end{array}$ & $\begin{array}{l}\text { No. of } \\
R / C\end{array}$ & Tunability & $\begin{array}{l}\text { No passive/active } \\
\text { matching constraints }\end{array}$ & $\begin{array}{l}\text { Type of } \\
\text { response }\end{array}$ & $\begin{array}{l}\text { Technology } \\
(\mu \mathrm{m})\end{array}$ & $\begin{array}{l}\text { Power supplies } \\
\text { (V) }\end{array}$ \\
\hline$[1]^{\S}$ & DVCC+ & 1 & 12 & $1 / 2$ & no & no & non-inverting & 0.5 & \pm 2.5 \\
\hline [2] & DVCC+ & 2 & 24 & $1 / 1$ & no & yes & both $\leftrightarrow$ & 0.18 & \pm 1.5 \\
\hline [3] & CCCII- & 2 & $34^{*}$ & $0 / 1$ & yes & no & inverting & $\mathrm{BJT}$ & \pm 2.5 \\
\hline [4] & CCCII + / OpAmp & 2 & $14^{*} / \mathrm{D}$ & $0 / 2$ & yes & no & inverting & $\mathrm{BJT} / \mathrm{D}$ & $\pm 2.5 /-$ \\
\hline$[5]^{\S}$ & CCCII+ / OpAmp & 3 & $28^{*} / \mathrm{D}$ & $0 / 2$ & yes & no & inverting & $\mathrm{BJT} / \mathrm{D}$ & $\pm 2.5 /-$ \\
\hline [6] & DVCC- & 2 & 26 & $0 / 1$ & yes & yes & non-inverting & 0.5 & \pm 2.5 \\
\hline [7] & C-CDBA & 3 & $65^{*}$ & $0 / 1$ & yes & no & inverting & 0.35 & \pm 2.5 \\
\hline [8] & $\mathrm{CCCII}+/ \mathrm{DV}-\mathrm{VB}$ & 2 & $\mathrm{D}$ & $0 / 1$ & yes & yes & non-inverting & $\mathrm{D}$ & - \\
\hline [9] & C-ICDBA & 1 & $30^{*}$ & $0 / 1$ & yes & yes & non-inverting & 0.35 & \pm 2.5 \\
\hline [10] & CC-VCIII- & 1 & $22^{*}$ & $0 / 1$ & yes & yes & non-inverting & 0.35 & \pm 2.5 \\
\hline [11] & CCCII+ / FD-OpAmp & 2 & $13^{*} / \mathrm{D}$ & $0 / 1$ & yes & yes & both simultaneously & $\mathrm{BJT} / \mathrm{D}$ & \pm 1.5 \\
\hline [12] & IUGA & 1 & $5^{*}$ & $0 / 1$ & yes & yes & inverting & 0.35 & \pm 1.5 \\
\hline [13] & DDCC & 2 & $34^{+}$ & $0 / 1$ & yes & yes & non-inverting & 0.35 & \pm 1.5 \\
\hline [14] & UVC & 1 & $41^{*+}$ & $0 / 1$ & yes & yes & both simultaneously & 0.35 & \pm 2.5 \\
\hline$[15]$ & UVC & 1 & $44^{*+}$ & $0 / 1$ & yes & no & both simultaneously & 0.35 & \pm 2.5 \\
\hline [16] & IVB & 2 & $5^{+}$ & $0 / 1$ & yes & yes & both $\leftrightarrow$ & 0.18 & \pm 0.9 \\
\hline [17] & VD-DIBA & 1 & $\mathrm{D}$ & $0 / 1$ & yes & yes & non-inverting & $\mathrm{D}$ & - \\
\hline [18] & OTA & 1 & $\mathrm{D}$ & $0 / 2$ & yes & no & inverting & $\mathrm{D}$ & - \\
\hline [19] & OTA & 3 & $12^{*}$ & $0 / 1$ & yes & yes & non-inverting & 0.5 & \pm 3 \\
\hline [20] & CCCDTA & 1 & $25^{*}$ & $0 / 1$ & yes & no & inverting & BJT & \pm 1.5 \\
\hline [21] & UVC / OTA & 2 & $33^{* \&}$ & $0 / 1$ & yes & Yes & both simultaneously & BJT & \pm 2 \\
\hline [22] & MO-СCСCTA & 1 & $29^{*}$ & $0 / 1$ & yes & no & non-inverting & BJT & \pm 2 \\
\hline [23] & OTA / UGDA & 2 & $22^{*}$ & $0 / 1$ & yes & yes & inverting & 0.35 & \pm 2.5 \\
\hline This work & VDIBA & 1 & $6^{*}$ & $0 / 1$ & yes & yes & both simultaneously & 0.18 & \pm 0.9 \\
\hline Note: & $\begin{array}{l}{ }^{8} \text { Considered circuit: }[1 \\
{ }^{\#} \text { Refer Appendix for } n \\
{ }^{\wedge} \text { Minimal configuratio } \\
{ }^{*} \text { Ideal current sources } \\
{ }^{\&} \text { Ideal voltage buffers } \\
\text { D Discrete ICs used: [ } \\
{ }^{+} \text {Including MOSFETs } \\
\leftrightarrow \text { By interchanging the } \\
- \text { Not mentioned }\end{array}$ & $\begin{array}{l}\text { simulate } \\
\text { menclatu } \\
\text { assumed } \\
\text { ssumed } \\
\text { ssumed } \\
\mu \mathrm{A} 741 \text {; } \\
\text { eplacing } \\
\text { esistor a }\end{array}$ & $\begin{array}{l}\text { [5] OP-27; } \\
\text { voltage-cont } \\
\text { nd capacitor }\end{array}$ & $\begin{array}{l}\text { and [1 } \\
\text { olled res }\end{array}$ & $\begin{array}{l}\text { 7] OPA } 860 \\
\text { istor }\end{array}$ & and AD8130; [11] LTC & 6403-1; [18] CA3080 & & \\
\hline
\end{tabular}

This paper reports another 'voltage differencing' element, namely the voltage differencing inverting buffered amplifier (VDIBA), which has simpler active structure than VD-DIBA [17], because there is no need of a difference amplifier at its second stage. Moreover, the proposed resistorless first-order VM APF using single VDIBA and one capacitor provides both inverting and non-inverting all-pass responses simultaneously at two different output nodes. It is worth mention that only circuits in [11], [14], [15], and [21] have such exclusive advantage. To validate the applicability of the new APF, a second-order APF and four-phase quadrature oscillator circuits are presented. SPICE simulation and experimental measurement results are included to support the theory.

\section{Circuit description}

The voltage differencing inverting buffered amplifier (VDIBA) is a new four-terminal active device with electronic tuning, circuit symbol and behavioral model of which are shown in Figs. 1(a) and 1(b), respectively. From the model it can be seen that the VDIBA has a pair of high-impedance voltage inputs $v+$ and $v-$, a high-impedance current output $z$, and low-impedance voltage output $w$ - The input stage of VDIBA can be easily implemented by a differentialinput single-output OTA, which converts the input

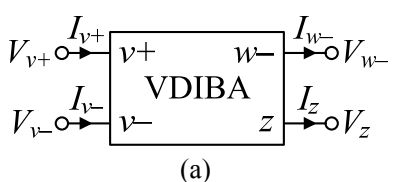

VDIBA

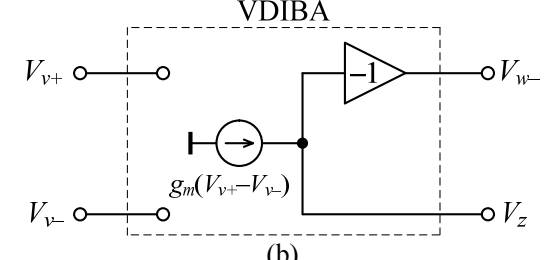

(b)

Fig. 1. (a) Circuit symbol, (b) behavioral model of VDIBA

voltage to output current that flows out at the $z$ terminal. The output stage can be formed by unity-gain IVB. Since both stages can be implemented by commercially available integrated circuits (ICs), and moreover it contains OTA, the introduced active element is attractive for resistorless and electronically controllable circuit applications.

Using standard notation, the relationship between port currents and voltages of a VDIBA can be described by the following hybrid matrix:

$$
\left[\begin{array}{c}
I_{v+} \\
I_{v-} \\
I_{z} \\
V_{w-}
\end{array}\right]=\left[\begin{array}{cccc}
0 & 0 & 0 & 0 \\
0 & 0 & 0 & 0 \\
g_{m} & -g_{m} & 0 & 0 \\
0 & 0 & -\beta & 0
\end{array}\right]\left[\begin{array}{c}
V_{v+} \\
V_{v-} \\
V_{z} \\
I_{w-}
\end{array}\right],
$$




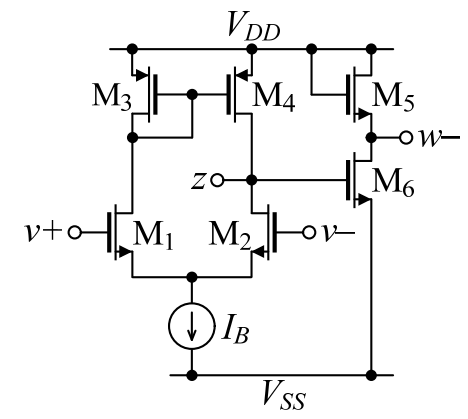

Fig. 2. CMOS implementation of VDIBA

where $g_{m}$ and $\beta$ represent transconductance and nonideal voltage gain of VDIBA, respectively. The value of $\beta$ in an ideal VDIBA is equal to unity.

The CMOS implementation of the VDIBA is shown in Fig. 2. The circuit is composed of an active loaded differential pair (transistors $\mathrm{M}_{1}-\mathrm{M}_{4}$ ) cascaded with a unity-gain inverting voltage buffer (matched transistors $\mathrm{M}_{5}$ and $\mathrm{M}_{6}$ ). The input/output terminal resistances of the CMOS VDIBA shown in Fig. 2 can be found as:

$$
\begin{gathered}
R_{o w-} \cong \frac{1}{g_{m 5}} \| r_{o 6}, \\
R_{o z} \cong r_{o 4} \| r_{o 2}, \\
R_{v+}=R_{v-} \cong \infty,
\end{gathered}
$$

where $g_{m i}$ and $r_{o i}$ represent the transconductance and output resistance of the $i$-th transistor, respectively. From Eqs. (2a)-(2c) it can be seen that while the output terminal $(w-)$ can exhibit low resistance by selecting large transistor $\mathrm{M}_{5}$ (and $\mathrm{M}_{6}$ due to the matching condition requirement), the input terminals $(v+$ and $v-)$ as well as the $z$ terminal have high resistances.

The proposed new first-order VM APF using single active element and a capacitor is shown in Fig. 3. Considering an ideal VDIBA $(\beta=1)$, routine analysis of the circuit gives the following transfer functions (TFs):

$$
\begin{gathered}
T_{1}(s)=\frac{V_{o 1}}{V_{i n}}=\frac{s C-g_{m}}{s C+g_{m}}, \\
T_{2}(s)=\frac{V_{o 2}}{V_{i n}}=-\frac{s C-g_{m}}{s C+g_{m}} .
\end{gathered}
$$

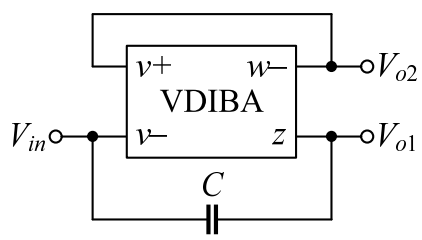

Fig. 3. Proposed resistorless dual-output VM all-pass filter with electronic tuning
The phase responses of the TFs (3a) and (3b) are calculated as:

$$
\begin{gathered}
\varphi_{1}(\omega)=180^{\circ}-2 \tan ^{-1}\left(\frac{\omega C}{g_{m}}\right), \\
\varphi_{2}(\omega)=-2 \tan ^{-1}\left(\frac{\omega C}{g_{m}}\right) .
\end{gathered}
$$

Hence, from the above equations it can be seen that the proposed configuration can simultaneously provide phase shifting both between $\pi$ (at $\omega=0$ ) to 0 (at $\omega=\infty)$ and $0($ at $\omega=0)$ to $-\pi($ at $\omega=\infty)$, at output terminals $V_{o 1}$ and $V_{o 2}$, respectively.

From Eqs. (3a) and (3b), the pole frequency $\omega_{p}$ is expressed as:

$$
\omega_{p}=\frac{g_{m}}{C}
$$

Note that the $\omega_{p}$ can be easily tuned by adjusting the transconductance of VDIBA. The pole sensitivities of the proposed circuit are given as:

$$
S_{g_{m}}^{\omega_{p}}=-S_{C}^{\omega_{p}}=1
$$

which are not higher than unity in magnitude.

\section{Non-ideal and parasitic effects analysis}

Taking into account the non-ideal voltage gain $\beta$ of the VDIBA, TFs in Eqs. (3a) and (3b) convert to:

$$
\begin{gathered}
T_{1}(s)=\frac{V_{o 1}}{V_{i n}}=\frac{s C-g_{m}}{s C+\beta g_{m}}, \\
T_{2}(s)=\frac{V_{o 2}}{V_{i n}}=-\beta T_{1}(s),
\end{gathered}
$$

and non-ideal phase responses from TFs (7a) and (7b) are given as:

$$
\begin{gathered}
\varphi_{1}(\omega)=180^{\circ}-\tan ^{-1}\left(\frac{\omega C}{g_{m}}\right)-\tan ^{-1}\left(\frac{\omega C}{\beta g_{m}}\right), \\
\varphi_{2}(\omega)=-\tan ^{-1}\left(\frac{\omega C}{g_{m}}\right)-\tan ^{-1}\left(\frac{\omega C}{\beta g_{m}}\right) .
\end{gathered}
$$

Consequently, the pole frequency of the presented filter is found as:

$$
\omega_{p}=\frac{\beta g_{m}}{C}
$$

From Eq. (9) it can be realized that the single nonideality of the VDIBA slightly affects the filter 
parameters, however, this influence can be easily compensated by the transconductance of the VDIBA.

For a complete analysis of the circuit in Fig. 3, it is also important to take into account parasitic effects of the VDIBA. Detailed numerical simulation of the filter indicated that the main source of non-idealities is due to the finite output admittance $Y_{z}$ of the involved OTA stage of the VDIBA. Considering that this admittance is modeled by a parallel $R C$ circuit consisting of a nonideal output resistance $R_{z}$ and a non-ideal output capacitance $C_{z}$ and assuming the non-zero output resistance $R_{w-}$ of the $w$ - terminal, the matrix relationship of (1) changes as follows:

$$
\left[\begin{array}{c}
I_{v+} \\
I_{v-} \\
I_{z} \\
V_{w-}
\end{array}\right]=\left[\begin{array}{cccc}
0 & 0 & 0 & 0 \\
0 & 0 & 0 & 0 \\
g_{m} & -g_{m} & s C_{z}+\frac{1}{R_{z}} & 0 \\
0 & 0 & -\beta & R_{w-}
\end{array}\right]\left[\begin{array}{c}
V_{v+} \\
V_{v-} \\
V_{z} \\
I_{w-}
\end{array}\right] .
$$

Re-analysis of the proposed filter in Fig. 3, the ideal TFs (3a) and (3b) turns to be:

$$
\begin{gathered}
T_{1}(s)=\frac{V_{o 1}}{V_{i n}}=\frac{C}{C+C_{z}} \cdot \frac{s-g_{m} / C}{s+\left(\beta g_{m}+\frac{1}{R_{z}}\right) /\left(C+C_{z}\right)}, \\
T_{2}(s)=\frac{V_{o 2}}{V_{i n}}=-\beta T_{1}(s) .
\end{gathered}
$$

From Eq. (11a) it is noted that the filter has a constant magnitude slightly lower than unity, which is equal to $C /\left(C+C_{z}\right)$ provided that the following condition is met:

$$
\beta=1+\frac{C_{z}}{C}-\frac{1}{g_{m} R_{z}}
$$

Therefore, by replacing the involved unity gain IVB stage with an adjustable amplifier with the prescribed gain in Eq. (12), the above discussed non-ideal effects can be fully compensated, at the cost of having a constant magnitude slightly lower than unity.
At this point, we want to note an interesting and useful property of the proposed filter. The filter has a very accurate unit magnitude at very low and very high frequencies. To be specific, owing to the fact that there is a capacitor connected between the filter's input and output terminals and the capacitor behaves as a shortcircuit element at the very high frequencies, the filter has very accurate unit magnitude in this frequency region, inherently. It is also worth mention that the circuit in [12] has an identical feature.

On the other hand, at very low frequencies, the filter magnitude approximates to:

$$
\left.\frac{V_{o 1}}{V_{i n}}\right|_{S=0}=\frac{-g_{m} R_{z}}{1+\beta g_{m} R_{z}},
$$

which is the gain of the feedback loop in Fig. 3. This gain also is very close to unity since typical value of $R_{z}$ is much larger than $1 / g_{m}$.

From Eqs. (11a) and (11b) the non-ideal zero $\omega_{z}$ and pole $\omega_{p}$ frequencies including parasitics can be calculated as:

$$
\begin{gathered}
\omega_{z}=\frac{g_{m}}{C}, \\
\omega_{p}=\frac{\beta g_{m}+\frac{1}{R_{z}}}{C+C_{z}} .
\end{gathered}
$$

From Eq. (14b) it is clear that pole $\omega_{p}$ frequency is affected by the parasitics and non-idealities of the active element used, however, they can be minimized by:

(i) making the $\beta$ very close to unity and/or,

(ii) choosing $C » C_{z}$ and/or,

(iii) choosing $g_{m} \gg 1 / R_{z}$.

\section{Loading effect analysis}

In addition, the loading effects at both output terminals are also worth to be investigated. Assuming equal load $R_{L 1}=R_{L 2}=R_{L}$ and considering the nonidealities and parasitics of the VDIBA in Eq. (10), straightforward analysis gives the following voltage transfer functions:

$$
T_{1}(s)=\frac{V_{o 1}}{V_{\text {in }}}=\frac{\left(s C-g_{m}\right)\left(R_{L}+R_{w-}\right) R_{z}}{s\left(C R_{L} R_{z}+C_{z} R_{L} R_{z}+C R_{z} R_{w-}+C_{z} R_{z} R_{w-}\right)+R_{L}+R_{w-}+R_{z}+\frac{R_{z} R_{w-}}{R_{L}}+\beta R_{L} R_{z} g_{m}},
$$




$$
T_{2}(s)=\frac{V_{o 2}}{V_{\text {in }}}=-\beta T_{1}(s) .
$$

Assuming $R_{L} » R_{w-}$, TFs in Eqs. (15a) and (15b) turn to:

$$
\begin{gathered}
T_{1}(s)=\frac{V_{o 1}}{V_{\text {in }}}=\frac{s C-g_{m}}{s\left(C+C_{z}\right)+\beta g_{m}+\frac{1}{R_{z}}+\frac{1}{R_{L}}} \\
T_{2}(s)=\frac{V_{o 2}}{V_{i n}}=-\beta T_{1}(s) .
\end{gathered}
$$

Finally, considering $R_{z} » R_{L}$, TFs in Eqs. (16a) and (16b) change to:

$$
\begin{gathered}
T_{1}(s)=\frac{V_{o 1}}{V_{i n}}=\frac{s C-g_{m}}{s\left(C+C_{z}\right)+\beta g_{m}+\frac{1}{R_{L}}}, \\
T_{2}(s)=\frac{V_{o 2}}{V_{i n}}=-\beta T_{1}(s),
\end{gathered}
$$

and hence, the pole $\omega_{p}^{\prime}$ frequency in Eq. (14b) turns to be:

$$
\omega_{p}^{\prime}=\frac{\beta g_{m}+\frac{1}{R_{L}}}{C+C_{z}} .
$$

The active and passive sensitivities of the $\omega_{p}^{\prime}$ can be calculated as:

$$
\begin{gathered}
S_{C}^{\omega_{p}^{\prime}}=-\frac{1}{1+\frac{C_{z}}{C}}, S_{C_{z}}^{\omega_{p}^{\prime}}=-\frac{1}{1+\frac{C}{C_{z}}} \\
S_{\beta}^{\omega_{p}^{\prime}}=S_{g_{m}}^{\omega_{p}^{\prime}}=\frac{1}{1+\frac{1}{\beta g_{m} R_{L}}}, \quad S_{R_{L}}^{\omega_{p}^{\prime}}=-\frac{1}{1+\beta g_{m} R_{L}} .
\end{gathered}
$$

Additionally, using (9) in (18), between $\omega_{p}^{\prime}$ and $\omega_{p}$ the following relationship can be calculated:

$$
\omega_{p}^{\prime}=\frac{1}{R_{L}\left(C+C_{z}\right)}+\frac{C}{C+C_{z}} \omega_{p} .
$$

To illustrate the effect of the load, Eq. (20) was further investigated, as it is shown in Fig. 4. The calculation has been done for three different values of $R_{L}=\{1 ; 10 ; 100\} \mathrm{k} \Omega$ while keeping the $C$ and $C_{z}$ values identical with in the Section 5 listed once. From Fig. 4 it can be realized that for lower pole frequencies the effect of $R_{L}$ on the deviation of the pole frequency from its original value becomes dominant with respect to the parasitic effect $\left(C_{z}\right)$. Hence, lower values of $R_{L}$ restrict the proper operation of the proposed APF at lower pole frequencies, where a phase shift of $90^{\circ}$ must be obtained.

\section{Performance verifications}

\subsection{Simulation results}

To verify the theoretical study, the behavior of the introduced VDIBA shown in Fig. 2 has been verified by SPICE simulations with DC power supply voltages equal to $+V_{\mathrm{DD}}=-V_{\mathrm{SS}}=0.9 \mathrm{~V}$. In the design, transistors are modeled by the TSMC $0.18 \mu \mathrm{m}$ level- 7 CMOS process parameters $\quad\left(V_{\mathrm{THN}}=0.3725 \mathrm{~V}\right.$, $\mu_{\mathrm{N}}=259.5304 \mathrm{~cm}^{2} /(\mathrm{V} \cdot \mathrm{s}), \quad V_{\mathrm{THP}}=-0.3948 \mathrm{~V}$, $\left.\mu_{\mathrm{P}}=109.9762 \mathrm{~cm}^{2} /(\mathrm{V} \cdot \mathrm{s}), T_{\mathrm{OX}}=4.1 \mathrm{~nm}\right)[2]$. The aspect ratios of the OTA $\left(\mathrm{M}_{1}-\mathrm{M}_{4}\right)$ and the IVB $\left(\mathrm{M}_{5}\right.$ and $\left.\mathrm{M}_{6}\right)$ were chosen as $W / L_{(\mathrm{M} 1-\mathrm{M} 4)}=18 \mu \mathrm{m} / 1.08 \mu \mathrm{m}$ and $W / L_{(\mathrm{M} 5, \mathrm{M} 6)}=54 \mu \mathrm{m} / 0.18 \mu \mathrm{m}$, respectively. Note that the $W / L$ ratio of the transistors $\mathrm{M}_{5}$ and $\mathrm{M}_{6}$ should be selected sufficiently high to decrease the loading effect.

First of all, the performance of the VDIBA was tested by $\mathrm{AC}$ and $\mathrm{DC}$ analyses. The $\mathrm{AC}$ simulation results for both transconductance and voltage transfers of the VDIBA are shown in Figs. 5(a) and 5(b), respectively. In the simulations the bias current was selected as $I_{B}=100 \mu \mathrm{A}$, which results in $g_{m}$ approximately equal to $600 \mu \mathrm{A} / \mathrm{V}$ with $f_{-3 \mathrm{~dB}}$ frequency of $226.32 \mathrm{MHz}$. Subsequently, the obtained gain of the IVB voltage transfer shown in Fig. 5(b) is equal to $\beta=0.922$ and its $f_{-3 \mathrm{~dB}}$ frequency is found to be $51.93 \mathrm{GHz}$. Hence, the maximum operating frequency of the VDIBA is $f_{\max }=\min \left\{f_{\beta}, f_{g m}\right\} \approx 226.32 \mathrm{MHz}$. In addition, the $z$ and $w$ - terminal parasitic capacitance and resistances were found as $C_{z}=367 \mathrm{fF} \| R_{z}=131.93 \mathrm{k} \Omega$ and $R_{w-}=42.36 \Omega$, respectively. The DC characteristics such as plots of $I_{z}$

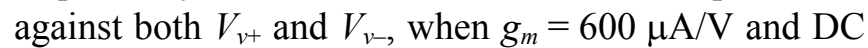
voltage characteristic of $V_{w-}$ against $V_{z}$ for the proposed VDIBA are shown in Figs. 6(a) and 6(b), respectively. The maximum values of terminal voltages without producing significant distortion are approximately computed as $\pm 200 \mathrm{mV}$ for the OTA and $-0.9 \mathrm{~V}$ to $+0.5 \mathrm{~V}$ for the IVB, respectively.

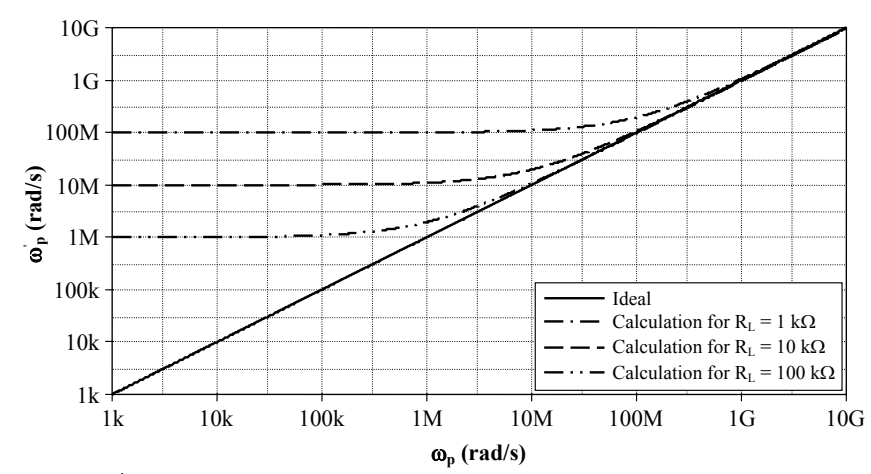

Fig. 4. $\omega_{p}^{\prime}$ versus $\omega_{p}$ for different values of load 


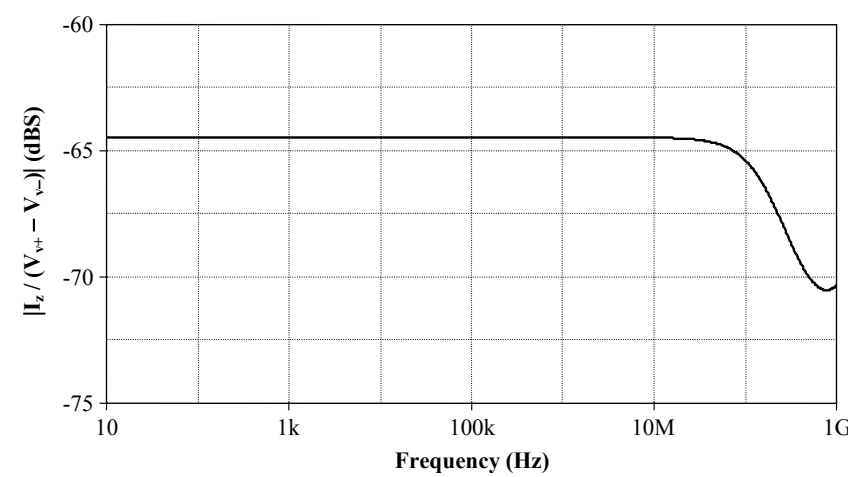

(a)

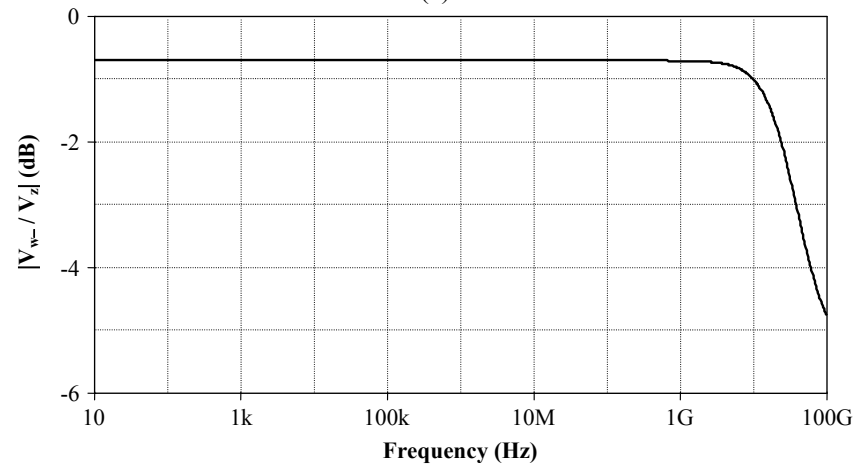

(b)

Fig. 5. AC analysis of VDIBA in Fig. 2: (a) transconductance gain and (b) voltage gain versus frequency

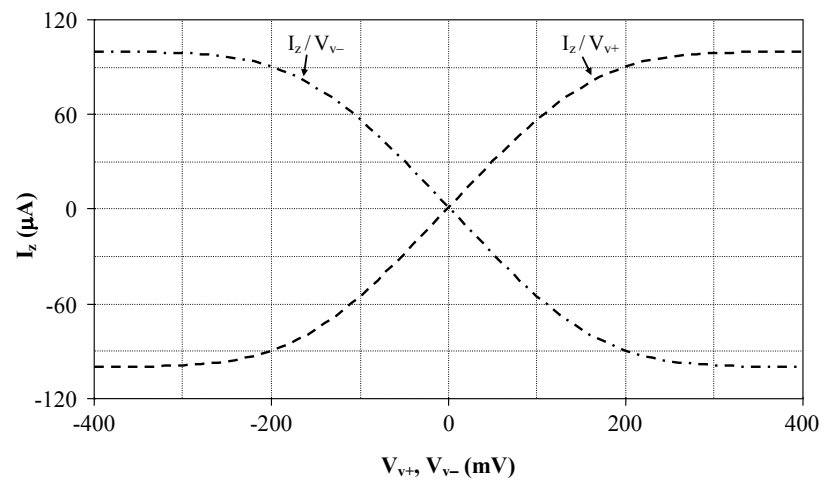

(a)

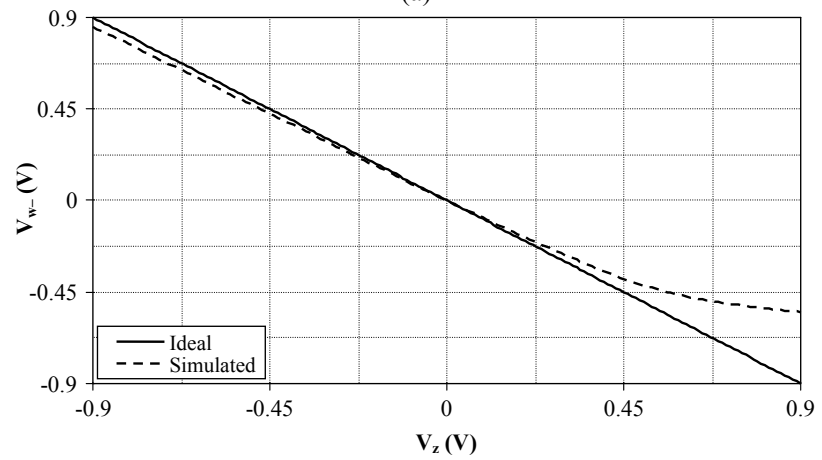

(b)

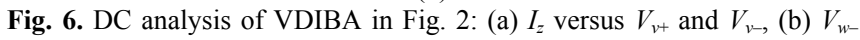
versus $V_{z}$

In order to verify the workability of the proposed VM APF in Fig. 3, it has been further analyzed using the designed CMOS implementation of the VDIBA in SPICE software. Figs. 7(a) and 7(b) show the ideal and simulated gain and phase responses illustrating the electronic tunability of the proposed filter. The pole

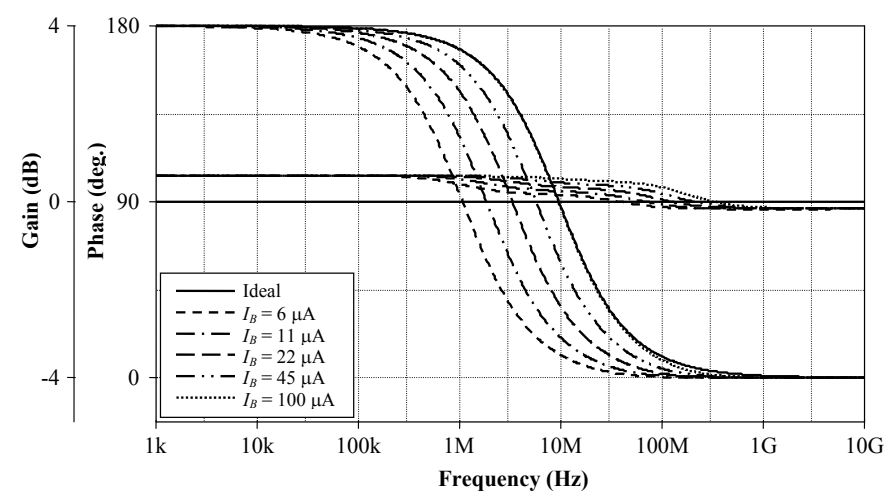

(a)

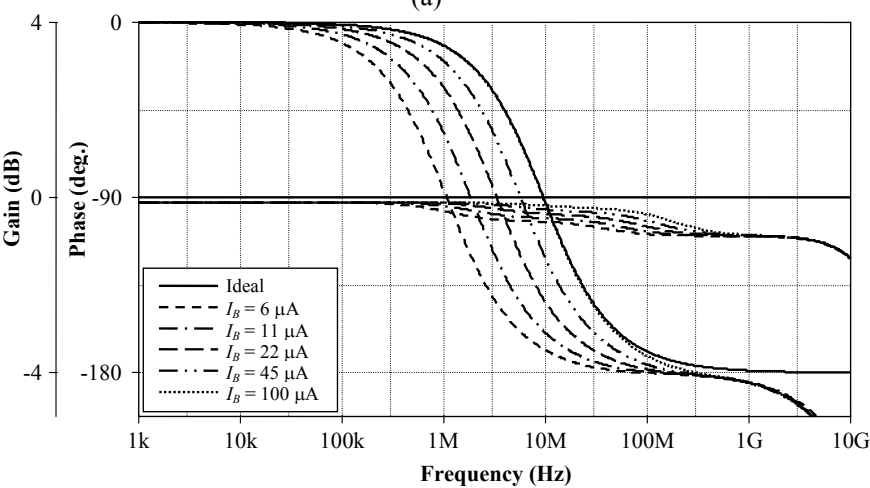

(b)

Fig. 7. Electronical tunability of the pole frequency by the bias current $I_{B}$ : (a) inverting, (b) non-inverting VM first-order all-pass filter responses

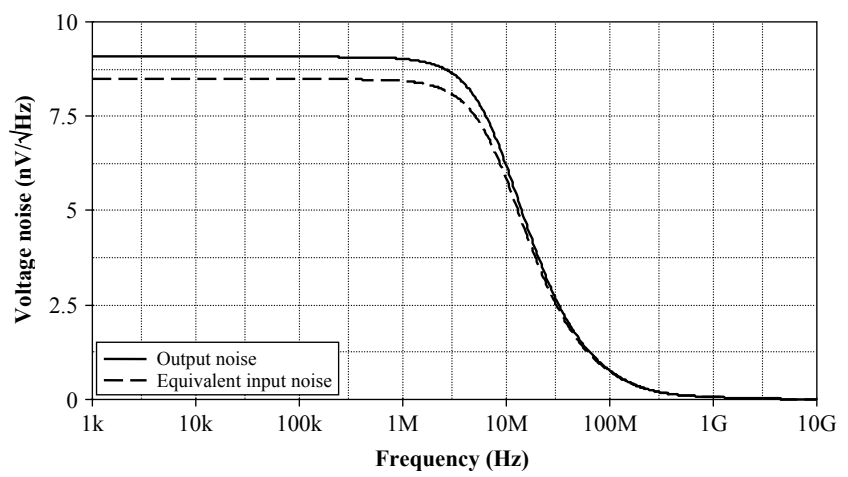

(a)

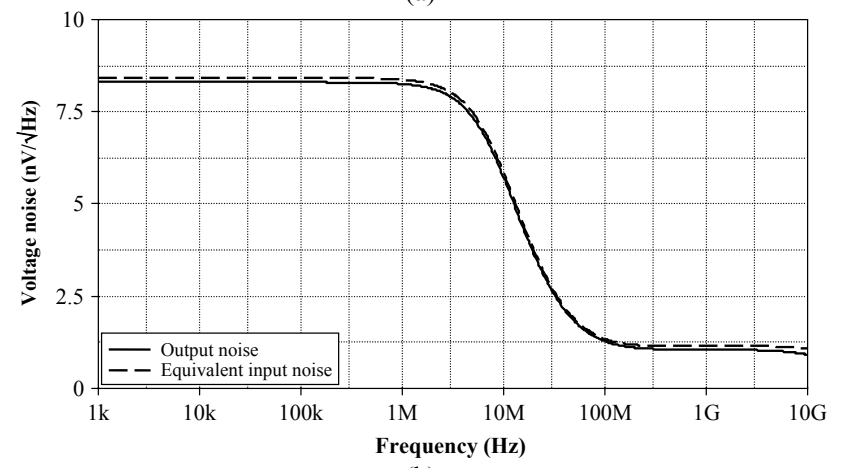

(b)

Fig. 8. Input and output noise variations for (a) $V_{o 1}$ and (b) $V_{o 2}$ versus frequency

frequency is varied for $f_{0} \cong\{1.07 ; 1.84 ; 3.31 ; 5.67$; $9.44\} \mathrm{MHz}$ via the bias current $I_{B}=\{6 ; 11 ; 22 ; 45$; $100\} \mu \mathrm{A}$, respectively. In all simulations the value of the capacitor $C$ has been selected as $9.6 \mathrm{pF}$. Note that the external capacitor $C$ appears parallel with $C_{g s 6}$ parasitic capacitance of the transistor $\mathrm{M}_{6}$, which value 
is equal to $461 \mathrm{fF}$. Theoretically, therefore, its total value equal to $C \approx 10 \mathrm{pF}$ should be taken into account. Hence, considering $I_{B}=100 \mu \mathrm{A}\left(g_{m}=600 \mu \mathrm{A} / \mathrm{V}\right)$, the $90^{\circ}$ phase shift is at pole frequency $f_{0} \cong 9.44 \mathrm{MHz}$, which is close to the ideal $f_{0}$ equal to $9.54 \mathrm{MHz}$. The obtained gains for the first and the second outputs are equal to 1.075 and 0.987 , respectively. The small discrepancy between ideal and simulated gain results can be attributed to the non-ideal voltage gain $\beta$ and the non-idealities of the active element used and hence in practice a precise design of the VDIBA should be considered to alleviate the non-ideal effects. Using the INOISE and ONOISE statements, the input and output noise behavior for both responses with respect to frequency have also been simulated, as it is shown in Figs. 8(a) and 8(b). The equivalent input/output noises for the first and the second responses at operating frequency $\left(f_{0} \cong 9.44 \mathrm{MHz}\right)$ are found as $6.02 / 6.39 \mathrm{nV} / \sqrt{\mathrm{Hz}}$ and $6.03 / 5.91 \mathrm{nV} / \sqrt{\mathrm{Hz}}$, respectively.

To illustrate the time-domain performance, transient analysis is performed to evaluate the voltage swing capability and phase errors of the filter as it is demonstrated in Fig. 9 while keeping the $I_{B}=100 \mu \mathrm{A}$ $\left(g_{m}=600 \mu \mathrm{A} / \mathrm{V}\right)$ and $C=9.6 \mathrm{pF}$. Note that the output waveforms are close to the input one. The total harmonic distortion (THD) variations with respect to amplitudes of the applied sinusoidal input voltages at $9.44 \mathrm{MHz}$ are shown in Fig. 10. An input with the amplitude of $100 \mathrm{mV}$ yields THD values of $1.81 \%$ and $1.86 \%$ for the first and second output of the proposed filter, respectively. In addition, the $+90^{\circ}$ and $-90^{\circ}$

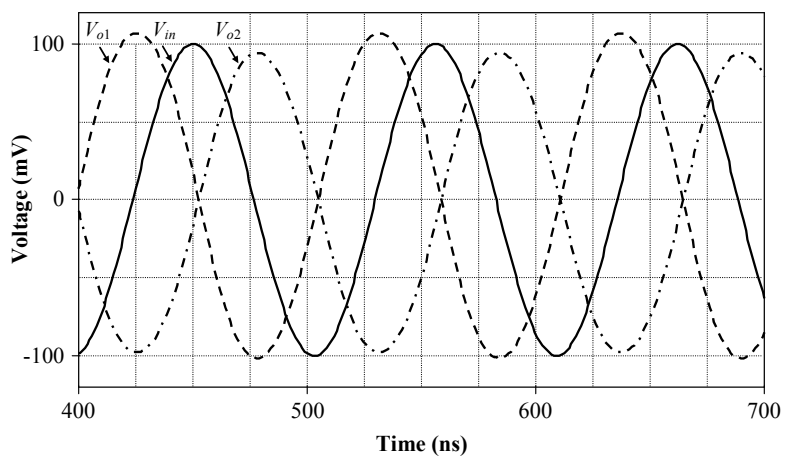

Fig. 9. Time-domain responses of the proposed all-pass filter at $9.44 \mathrm{MHz}$

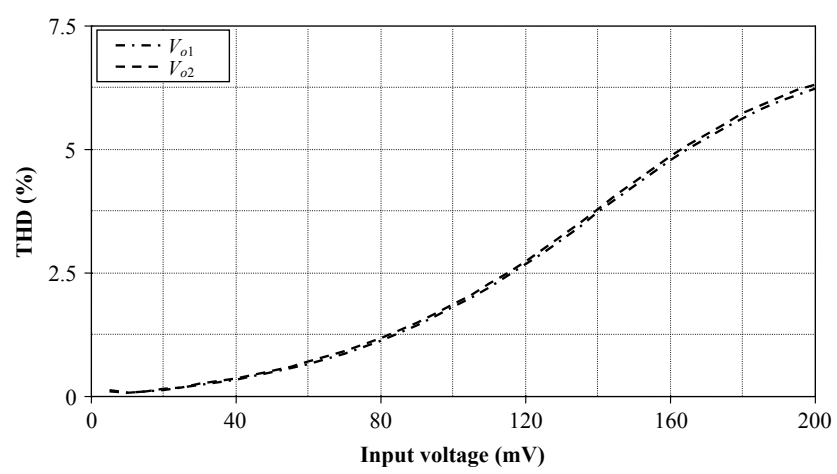

Fig. 10. THD variation of the proposed all-pass filter for both responses against applied input voltage at $9.44 \mathrm{MHz}$ phase shifts in the first and the second outputs against the input at pole frequency $9.44 \mathrm{MHz}$ are also illustrated in the Lissajous patterns shown in Figs. 11(a) and 11(b), respectively. The total power dissipation of the circuit is found to be $10.5 \mathrm{~mW}$.

\subsection{Measurement results}

In order to confirm the theoretical results, the behavior of the proposed APF has also been verified by experimental measurements using networkspectrum analyzer Agilent 4395A, function generator Agilent 33521A, and four-channel oscilloscope Agilent DSOX2014A. In measurements the VDIBA was implemented based on the structure illustrated in Fig. 12 using readily available ICs OPA860 [27] by Texas Instruments. The DC power supply voltages were equal to $\pm 5 \mathrm{~V}$ and the resistor $R_{A D J}$ (see [27]) was chosen as $270 \Omega$. The OPA860 contains the so-called 'diamond' transistor (DT) and fast voltage buffer (VB). In the input stage, in order to increase the linearity of collector current versus input voltage $V_{d}$, the $\mathrm{DT}_{1}$ is complemented with degeneration resistor $R_{G} \gg 1 / g_{m T}$, added in series to the emitter, where the $g_{m T}$ is the DT transconductance. Then the total transconductance decreases to the approximate value $1 / R_{G}$ [17]. The $\mathrm{DT}_{2}$ together with $R_{E}$ and $R_{C}$ represent the IVB with the gain of the amplifier calculated as $\beta \cong-R_{C} / R_{E}$ [17]. The input stage and the IVB are separated by the $\mathrm{VB}_{2}$.

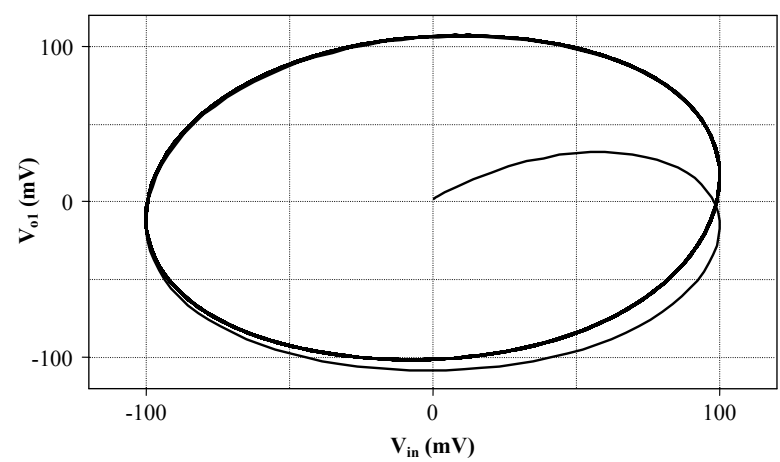

(a)

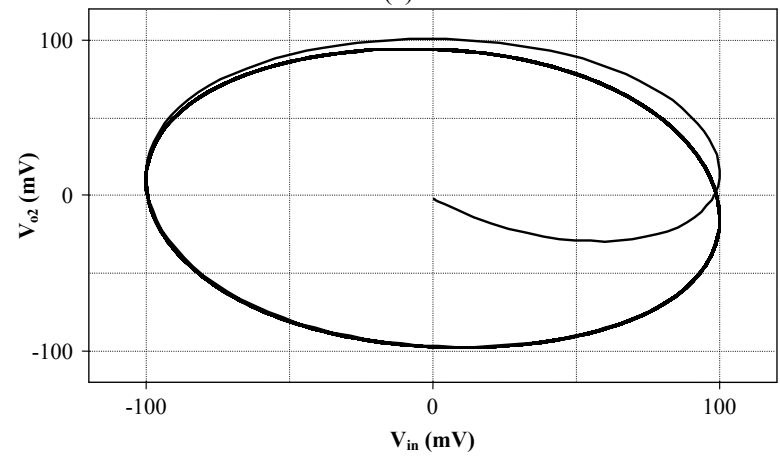

(b)

Fig. 11. Lissajous patterns showing (a) $+90^{\circ}$ phase shift of $V_{o 1}$ and (b) $-90^{\circ}$ phase shift of $V_{o 2}$ against input voltage at $9.44 \mathrm{MHz}$ 


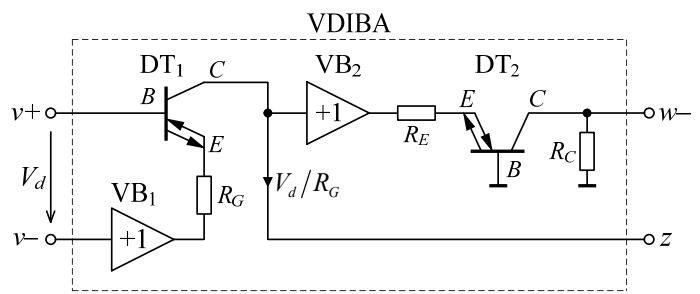

Fig. 12. VDIBA implementation by two Analog Devices ICs OPA860

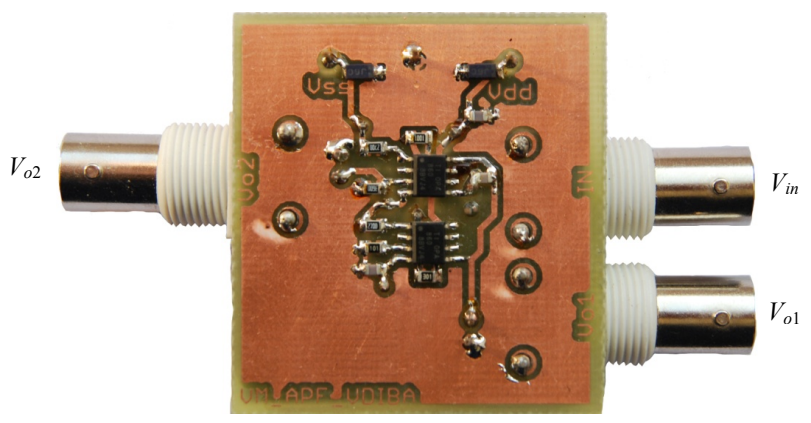

Fig. 13. The PCB prototype of the proposed all-pass filter based on VDIBA implementation from Fig. 12

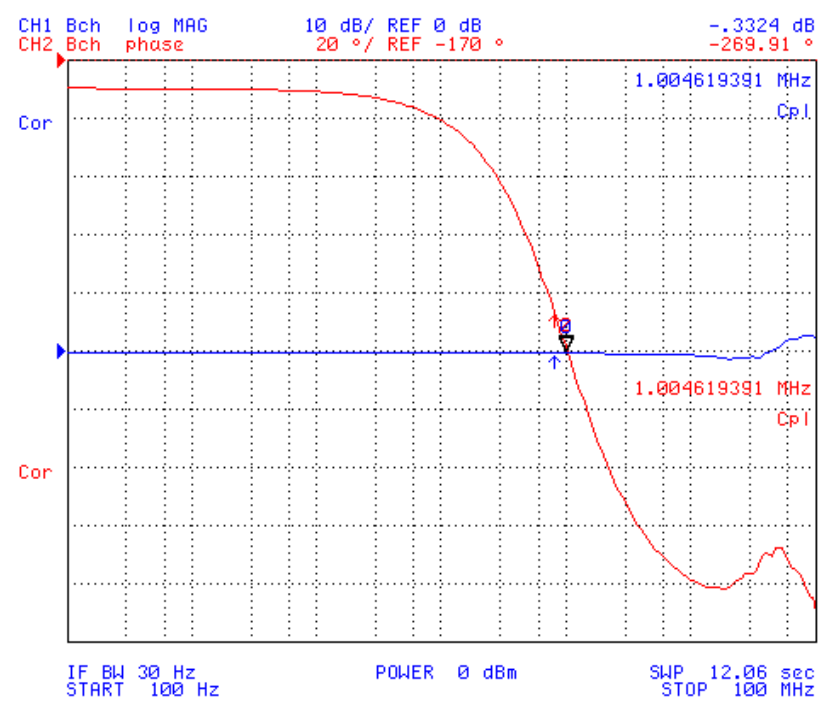

(a)

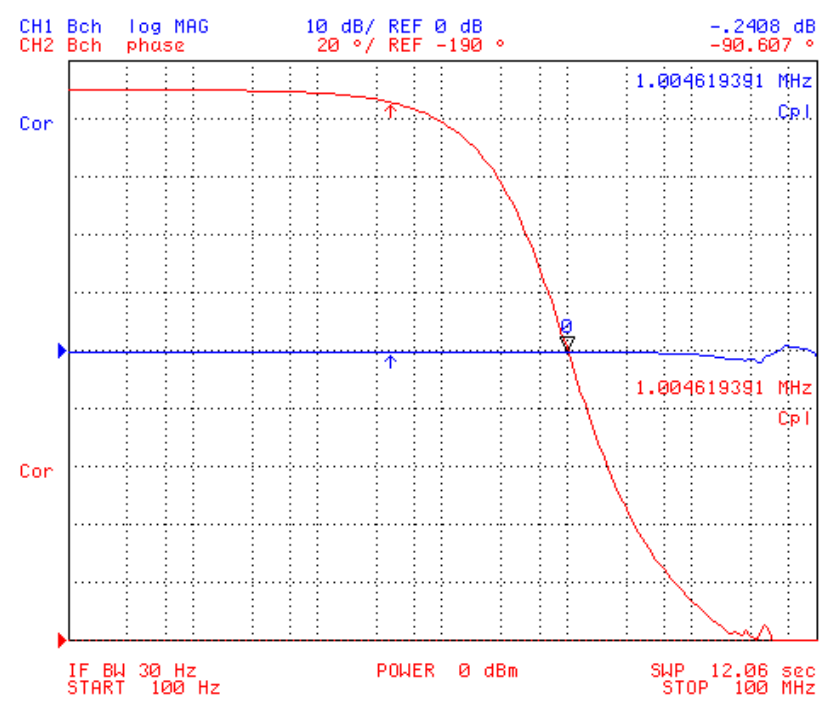

(b)

Fig. 14. Measured gain and phase characteristics of the proposed all-pass filter: (a) $T_{1}(s)$, (b) $T_{2}(s)$

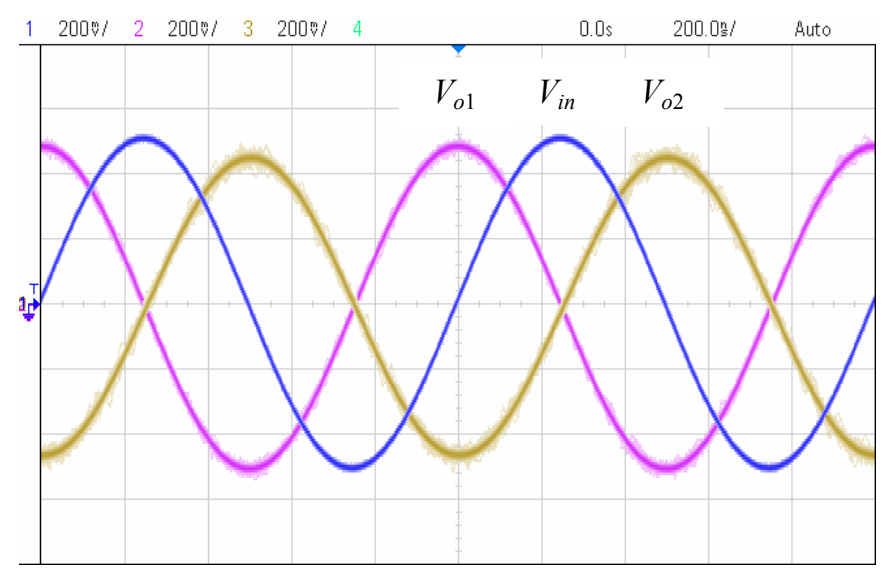

Fig. 15. Measured time-domain responses of the proposed all-pass filter at $1 \mathrm{MHz}$

The developed PCB (printed circuit board) is shown in Fig. 13. In all measurements the values of the resistors $R_{E}$ and $R_{C}$ have been chosen as $157 \Omega$ and $172 \Omega$ to improve the gain of the IVB, respectively. In the proposed filter, the value of the capacitor $C$ has been selected as $150 \mathrm{pF}$ and value of the degeneration resistor $R_{G}$ was set to $1 \mathrm{k} \Omega$. In this case the $90^{\circ}$ phase shift is at $f_{0} \cong 1 \mathrm{MHz}$ and the results are shown in Figs. 14(a) and 14(b), respectively. The time-domain responses of the measured APF are shown in Fig. 15 in which a sine-wave input of $500 \mathrm{mV}$ amplitude and frequency of $1 \mathrm{MHz}$ was applied to the filter. Subsequently, the Fourier spectrum of both output signals, showing a high selectivity for the applied signal frequency, is shown in Figs. 16(a) and 16(b), respectively. The THDs at this frequency are found as $1.19 \%$ and $1.11 \%$ for the first and second output of the proposed filter, respectively.

From the simulation results and experimental measurements it can be seen that the final solution is in good agreement with the theory.

\section{Applications of the proposed filter}

In this section, the proposed VM APF in Fig. 3 is used as basic building block of more complex circuits. To the best of the authors' knowledge, the given applications based on the new APF topology are also new and unpublished.

\subsection{Second-order all-pass filter}

To illustrate the utility of the proposed first-order APF, a new dual-output second-order all-pass filter is proposed by connecting in cascade two APFs in an open loop. The proposed circuit in Fig. 17 only employs two VDIBAs and two capacitors. Taking into account the non-ideal voltage gain $\beta_{i}(i=1,2)$ of VDIBAs, routine analysis gives the following voltage TFs: 


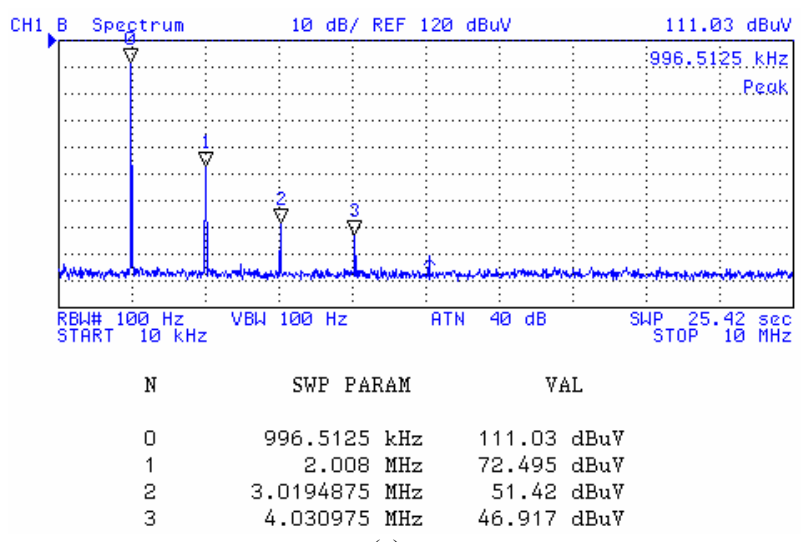

(a)

Fig. 16. Measured Fourier spectrum of the output signals: (a) $V_{o 1}$, (b) $V_{o 2}$

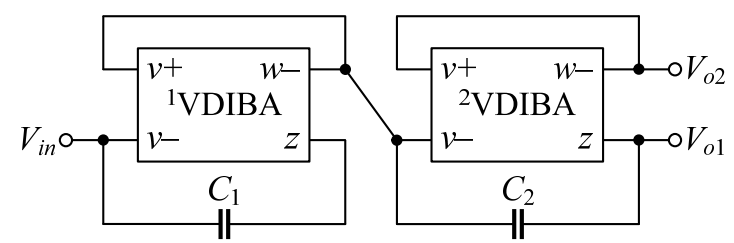

Fig. 17. Proposed resistorless dual-output VM second-order all-pass filter

$$
\begin{gathered}
T_{3}(s)=\frac{V_{o 1}}{V_{i n}}=-\beta_{1} \frac{s^{2}-s\left(\frac{g_{m 1}}{C_{1}}+\frac{g_{m 2}}{C_{2}}\right)+\frac{g_{m 1} g_{m 2}}{C_{1} C_{2}}}{s^{2}+s\left(\frac{\beta_{1} g_{m 1}}{C_{1}}+\frac{\beta_{2} g_{m 2}}{C_{2}}\right)+\frac{\beta_{1} \beta_{2} g_{m 1} g_{m 2}}{C_{1} C_{2}}}, \\
T_{4}(s)=\frac{V_{o 2}}{V_{i n}}=-\beta_{2} T_{3}(s) .
\end{gathered}
$$

Hence, the designed second-order APF configuration can simultaneously provide phase shifting both between $+\pi($ at $\omega=0$ ) to $-\pi$ (at $\omega=\infty$ ) and $0($ at $\omega=0)$ to $-2 \pi($ at $\omega=\infty)$, at output terminals $V_{o 1}$ and $V_{o 2}$, respectively.

From Eqs. (21a) and (21b), the angular resonance frequency $\left(\omega_{0}\right)$ and the quality factor $(Q)$ are given by:

$$
\omega_{0}=\sqrt{\frac{\beta_{1} \beta_{2} g_{m 1} g_{m 2}}{C_{1} C_{2}}}, \quad Q=\frac{\sqrt{\beta_{1} \beta_{2} g_{m 1} g_{m 2} C_{1} C_{2}}}{\beta_{1} g_{m 1} C_{2}+\beta_{2} g_{m 2} C_{1}} .
$$

From Eq. (22) it is evident that the proposed filter circuit realizes only relatively low $Q$ values and hence the new circuit is not suitable for synthesis of higherorder filters. It may be noted that the realized $\omega$ and $Q$ values can be changed electronically through $g_{m 1}$ and $g_{m 2}$. However, considering equal transconductances of both VDIBAs $\left(g_{m 1}=g_{m 2}\right)$ and constant passive elements, the $Q$ value of the circuit in Fig. 17 is fixed. Hence, this makes the circuit good for fixed $Q$ applications [28]. It is thus to be concluded that the new proposed circuit provides useful active- $C$ dualoutput VM second-order all-pass filtering option with minimum components and low transistor count.

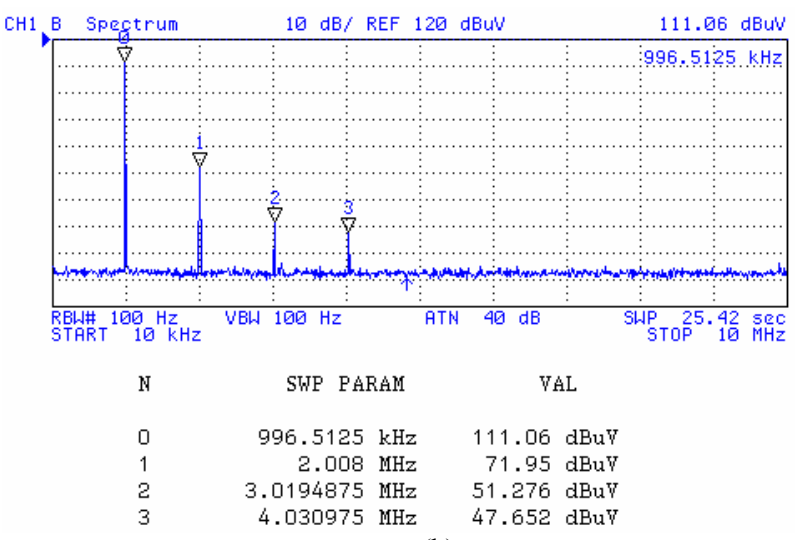

(b)

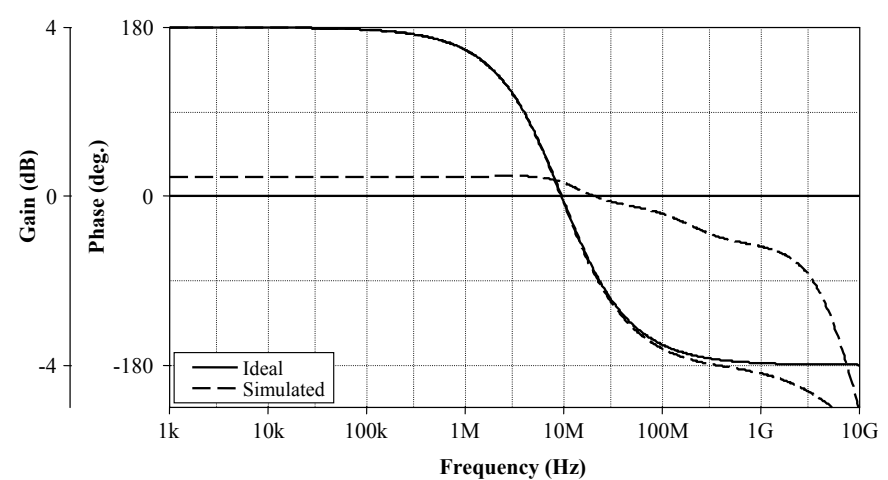

(a)

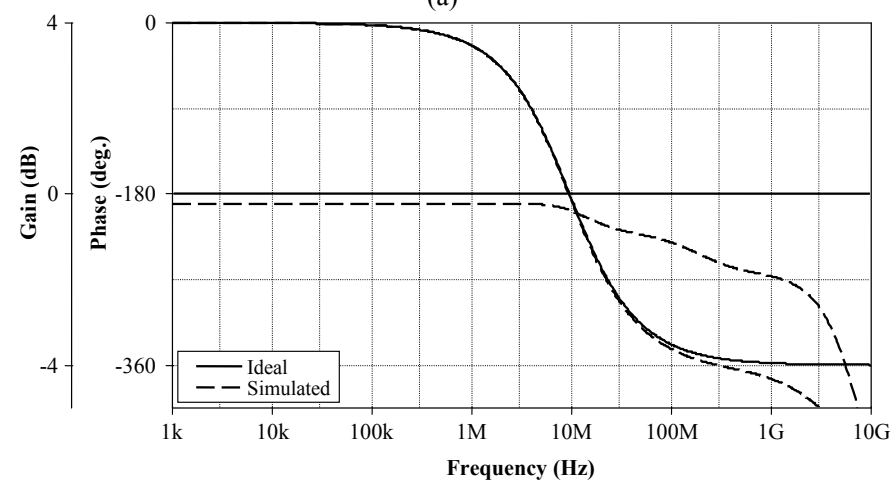

(b)

Fig. 18. Ideal and simulated gain and phase responses of the proposed VM second-order all-pass filter: (a) inverting $\left(V_{o 1}\right)$, (b) non-inverting $\left(V_{o 2}\right)$ responses

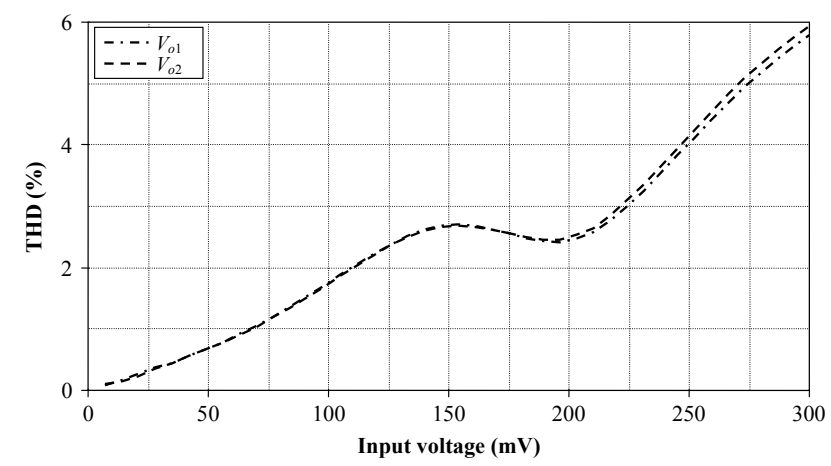

Fig. 19. THD variation of the proposed second-order all-pass filter for both responses against applied input voltage at $9.32 \mathrm{MHz}$

The SPICE verification of the new filter is given in Fig. 18, which show the ideal and simulated gain and phase responses for both outputs. In the simulations the values of capacitors $C_{1}=C_{2}$ have been selected as $9.6 \mathrm{pF}$ with consideration of parasitic capacitance of $C_{g s 6 i}=461 \mathrm{fF}$ of the transistor $\mathrm{M}_{6}$ for $i$ th VDIBA 
$(i=1,2)$. Hence, theoretically their total value are equal to $C_{1}=C_{2} \approx 10 \mathrm{pF}$. Considering $I_{B 1}=I_{B 2}=100 \mu \mathrm{A} \quad\left(g_{m}=600 \mu \mathrm{A} / \mathrm{V}\right)$, the theoretical angular resonant frequency is $f_{0} \cong 9.51 \mathrm{MHz}$, whereas the simulated value is $9.32 \mathrm{MHz}$, which is $1.9 \%$ in relative error. The THD variations with respect to amplitudes of the applied sinusoidal input voltages at 9.32 MHz are shown in Fig. 19. An input with the amplitude of $100 \mathrm{mV}$ yields THD values of $1.75 \%$ and $1.74 \%$ for the first and second output of the proposed second-order all-pass filter, respectively.

\subsection{Four-phase quadrature oscillator}

As another application example, a VM four-phase quadrature oscillator is given by connecting the proposed APF in cascade to a lossy integrator in a closed loop. It is well-known that quadrature oscillators are important circuits for various communication applications, wherein there is a requirement of multiple sinusoids that are $90^{\circ}$ phase shifted, e.g. in quadrature mixers and single-sideband modulators, or for measurement purposes in the vector generator or selective voltmeters. Here proposed new circuit shown in Fig. 20 consists of two VDIBAs, two capacitors, and a single resistor. Routine circuit analysis yields the following characteristic equation (CE):

\section{$\mathrm{CE}$ :}

$s^{2} C_{1} C_{2} R+s\left(C_{1}+C_{2} g_{m 1} R-2 C_{1} g_{m 2} R\right)+g_{m 1}=0$.

For the start-up of oscillation, the roots of the $\mathrm{CE}$ should be in the right-hand plane, which indicates that the coefficient of ' $s$ ' term in Eq. (23) should be negative. Replacing $s=j \omega$ in Eq. (23), the frequency of oscillation (FO) and the condition of oscillation (CO) can be evaluated as:

$$
\begin{gathered}
\text { FO }: \quad \omega_{0}=\sqrt{\frac{g_{m 1}}{C_{1} C_{2} R}}, \\
\mathrm{CO}: \quad g_{m 2} \geq \frac{1}{2}\left(\frac{1}{R}+g_{m 1} \frac{C_{2}}{C_{1}}\right) .
\end{gathered}
$$

From Eq. (24a) and (24b), it is clear that the FO can be controlled by adjusting the value of the resistor $R$ and/or by varying the control current $I_{B 1}$ of $g_{m 1}$.

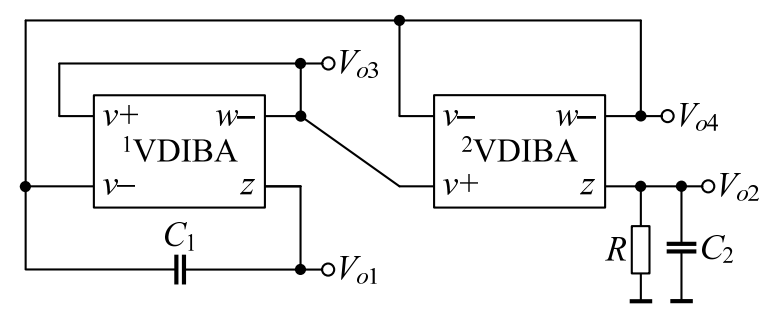

Fig. 20. Proposed VM four-phase quadrature oscillator

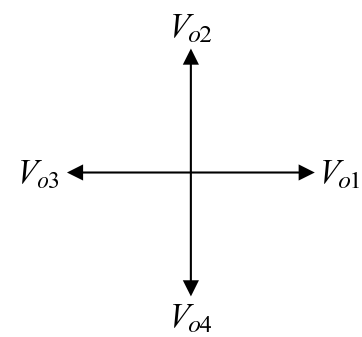

Fig. 21. Phasor diagram of four-phase oscillator

Assuming that the used external capacitors and the transconductance of both VDIBAs are equal, i.e. $C_{1}=C_{2}$ and $g_{m 1}=g_{m 2}$, the relationship between four quadrature output voltages $V_{o 1}, V_{o 2}, V_{o 3}$, and $V_{o 4}$ can be expressed as:

$$
\frac{V_{o 1}}{V_{o 2}}=-j, \quad \frac{V_{o 2}}{V_{o 3}}=-j, \quad \frac{V_{o 1}}{V_{o 4}}=j,
$$

ensuring the output voltages $V_{o 2}-V_{o l}, V_{o 3}-V_{o 2}, V_{o 4}-V_{o 3}$, and $V_{o 1}-V_{o 4}$ to be quadrature (in Fig. 21 the phase differences are $\phi=90^{\circ}$ ) and have equal amplitudes.

Assuming the non-ideal behavior of the active elements $\left(\beta_{i}\right)$, the $\mathrm{CE}, \mathrm{FO}$, and the $\mathrm{CO}$ in Eqs. (23), (24a), and (24b) change to:

$$
\begin{aligned}
& \mathrm{CE}: \quad s^{2} C_{1} C_{2} R+ \\
& +s\left[C_{1}+\beta_{1} C_{2} g_{m 1} R-\beta_{2} C_{1} g_{m 2} R\left(\beta_{1}+1\right)\right]+\beta_{1} g_{m 1}=0 \\
& \mathrm{FO}: \omega_{0}=\sqrt{\frac{\beta_{1} g_{m 1}}{C_{1} C_{2} R}}, \\
& \mathrm{CO}: \quad g_{m 2} \geq \frac{1}{\beta_{2}\left(\beta_{1}+1\right)}\left(\frac{1}{R}+\beta_{1} g_{m 1} \frac{C_{2}}{C_{1}}\right)
\end{aligned}
$$

From Eq. (26b) and (26c) it can be seen that the non-ideal behavior of the active elements affects both the frequency of oscillation and the condition of oscillation, however, $\mathrm{CO}$ can be satisfied by adjusting $g_{m 2}$ without affecting FO.

The proposed oscillator was designed with the following active parameters and the passive element values $\quad I_{B 1}=100 \mu \mathrm{A}, \quad R=1650 \Omega, \quad$ and $C_{1}=C_{2}=9.6 \mathrm{pF}$, respectively, to obtain the sinusoidal output waveforms with the oscillation frequency of $f_{0}=\omega_{0} / 2 \pi \cong 8.5 \mathrm{MHz}$. In practice, to ensure the startup (build-up) of oscillations and subsequently to satisfy the $\mathrm{CO}$ in Eq. (24b) the value of $I_{B 2}$ is chosen as $131 \mu \mathrm{A}$. The waveforms of the quadrature voltages are shown in Fig. 22. In addition, Fig. 23 shows the frequency spectrum of the output waveforms and the value of total harmonic distortion (THD) at all outputs are less than $2.25 \%$. The results are summarised in Table 2. 
Table 2. THD analysis of the proposed VM four-phase quadrature oscillator

\begin{tabular}{|c|c|c|c|c|c|}
\hline $\begin{array}{l}\text { Harmonic } \\
\text { no. }\end{array}$ & $\begin{array}{l}\text { Frequency } \\
(\mathrm{Hz})\end{array}$ & $\begin{array}{l}\text { Fourier } \\
\text { component }\end{array}$ & $\begin{array}{l}\text { Normalized } \\
\text { component }\end{array}$ & $\begin{array}{l}\text { Phase } \\
\text { (deg.) }\end{array}$ & $\begin{array}{l}\text { Normalized } \\
\text { phase (deg.) }\end{array}$ \\
\hline \multicolumn{6}{|l|}{ Output $V_{o 1}$} \\
\hline 1 & $8.500 \mathrm{E}+06$ & $1.146 \mathrm{E}-01$ & $1.000 \mathrm{E}+00$ & $1.722 \mathrm{E}+02$ & $0.000 \mathrm{E}+00$ \\
\hline 2 & $1.700 \mathrm{E}+07$ & $1.646 \mathrm{E}-03$ & $1.436 \mathrm{E}-02$ & $4.775 \mathrm{E}+01$ & $-2.966 \mathrm{E}+02$ \\
\hline 3 & $2.550 \mathrm{E}+07$ & $9.645 \mathrm{E}-04$ & $8.417 \mathrm{E}-03$ & $4.870 \mathrm{E}+01$ & $-4.679 \mathrm{E}+02$ \\
\hline 4 & $3.400 \mathrm{E}+07$ & $2.835 \mathrm{E}-04$ & $2.474 \mathrm{E}-03$ & $-3.536 \mathrm{E}+00$ & $-6.923 \mathrm{E}+02$ \\
\hline 5 & $4.250 \mathrm{E}+07$ & $2.144 \mathrm{E}-04$ & $1.871 \mathrm{E}-03$ & $1.120 \mathrm{E}+00$ & $-8.598 \mathrm{E}+02$ \\
\hline 6 & $5.100 \mathrm{E}+07$ & $1.663 \mathrm{E}-04$ & $1.451 \mathrm{E}-03$ & $5.455 \mathrm{E}+00$ & $-1.028 \mathrm{E}+03$ \\
\hline 7 & $5.950 \mathrm{E}+07$ & $1.419 \mathrm{E}-04$ & $1.238 \mathrm{E}-03$ & $6.807 \mathrm{E}+00$ & $-1.199 \mathrm{E}+03$ \\
\hline \multicolumn{6}{|l|}{ Output $V_{o 2}$} \\
\hline 1 & $8.500 \mathrm{E}+06$ & $1.204 \mathrm{E}-01$ & $1.000 \mathrm{E}+00$ & $-9.530 \mathrm{E}+01$ & $0.000 \mathrm{E}+00$ \\
\hline 2 & $1.700 \mathrm{E}+07$ & $1.697 \mathrm{E}-03$ & $1.409 \mathrm{E}-02$ & $1.488 \mathrm{E}+02$ & $3.394 \mathrm{E}+02$ \\
\hline 3 & $2.550 \mathrm{E}+07$ & $2.029 \mathrm{E}-03$ & $1.685 \mathrm{E}-02$ & $1.142 \mathrm{E}+02$ & $4.001 \mathrm{E}+02$ \\
\hline 4 & $3.400 \mathrm{E}+07$ & $1.532 \mathrm{E}-04$ & $1.273 \mathrm{E}-03$ & $3.413 \mathrm{E}+01$ & $4.153 \mathrm{E}+02$ \\
\hline 5 & $4.250 \mathrm{E}+07$ & $4.201 \mathrm{E}-05$ & $3.489 \mathrm{E}-04$ & $2.167 \mathrm{E}+01$ & $4.982 \mathrm{E}+02$ \\
\hline 6 & $5.100 \mathrm{E}+07$ & $3.499 \mathrm{E}-05$ & $2.906 \mathrm{E}-04$ & $4.685 \mathrm{E}+01$ & $6.187 \mathrm{E}+02$ \\
\hline 7 & $5.950 \mathrm{E}+07$ & $3.056 \mathrm{E}-05$ & $2.539 \mathrm{E}-04$ & $4.497 \mathrm{E}+01$ & $7.121 \mathrm{E}+02$ \\
\hline \multicolumn{6}{|l|}{ Output $V_{o 3}$} \\
\hline 1 & $8.500 \mathrm{E}+06$ & $1.056 \mathrm{E}-01$ & $1.000 \mathrm{E}+00$ & $-7.865 \mathrm{E}+00$ & $0.000 \mathrm{E}+00$ \\
\hline 2 & $1.700 \mathrm{E}+07$ & $2.078 \mathrm{E}-03$ & $1.967 \mathrm{E}-02$ & $-1.247 \mathrm{E}+02$ & $-1.090 \mathrm{E}+02$ \\
\hline 3 & $2.550 \mathrm{E}+07$ & $8.884 \mathrm{E}-04$ & $8.410 \mathrm{E}-03$ & $-1.328 \mathrm{E}+02$ & $-1.092 \mathrm{E}+02$ \\
\hline 4 & $3.400 \mathrm{E}+07$ & $2.654 \mathrm{E}-04$ & $2.512 \mathrm{E}-03$ & $1.746 \mathrm{E}+02$ & $2.060 \mathrm{E}+02$ \\
\hline 5 & $4.250 \mathrm{E}+07$ & $1.967 \mathrm{E}-04$ & $1.862 \mathrm{E}-03$ & $-1.793 \mathrm{E}+02$ & $-1.400 \mathrm{E}+02$ \\
\hline 6 & $5.100 \mathrm{E}+07$ & $1.525 \mathrm{E}-04$ & $1.443 \mathrm{E}-03$ & $-1.748 \mathrm{E}+02$ & $-1.276 \mathrm{E}+02$ \\
\hline 7 & $5.950 \mathrm{E}+07$ & $1.302 \mathrm{E}-04$ & $1.233 \mathrm{E}-03$ & $-1.734 \mathrm{E}+02$ & $-1.183 \mathrm{E}+02$ \\
\hline \multicolumn{6}{|l|}{ Output $V_{o 4}$} \\
\hline 1 & $8.500 \mathrm{E}+06$ & $1.085 \mathrm{E}-01$ & $1.000 \mathrm{E}+00$ & $8.344 \mathrm{E}+01$ & $0.000 \mathrm{E}+00$ \\
\hline 2 & $1.700 \mathrm{E}+07$ & $1.541 \mathrm{E}-03$ & $1.420 \mathrm{E}-02$ & $-1.535 \mathrm{E}+01$ & $-1.822 \mathrm{E}+02$ \\
\hline 3 & $2.550 \mathrm{E}+07$ & $1.872 \mathrm{E}-03$ & $1.726 \mathrm{E}-02$ & $-7.073 \mathrm{E}+01$ & $-3.211 \mathrm{E}+02$ \\
\hline 4 & $3.400 \mathrm{E}+07$ & $1.538 \mathrm{E}-04$ & $1.417 \mathrm{E}-03$ & $-1.445 \mathrm{E}+02$ & $-4.782 \mathrm{E}+02$ \\
\hline 5 & $4.250 \mathrm{E}+07$ & $4.131 \mathrm{E}-05$ & $3.807 \mathrm{E}-04$ & $-1.620 \mathrm{E}+02$ & $-5.792 \mathrm{E}+02$ \\
\hline 6 & $5.100 \mathrm{E}+07$ & $3.451 \mathrm{E}-05$ & $3.181 \mathrm{E}-04$ & $-1.372 \mathrm{E}+02$ & $-6.378 \mathrm{E}+02$ \\
\hline 7 & $5.950 \mathrm{E}+07$ & $3.018 \mathrm{E}-05$ & $2.782 \mathrm{E}-04$ & $-1.389 \mathrm{E}+02$ & $-7.230 \mathrm{E}+02$ \\
\hline
\end{tabular}

$V_{o 1}:$ DC component $=1.356817 \mathrm{E}-03 ; \mathrm{THD}=1.703811 \mathrm{E}+00$ per cent

$V_{o 2}:$ DC component $=-1.298111 \mathrm{E}-03 ;$ THD $=2.201311 \mathrm{E}+00$ per cent

$V_{o 3}:$ DC component $=-6.622693 \mathrm{E}-04 ; \mathrm{THD}=2.170434 \mathrm{E}+00$ per cent

$V_{o 4}: \mathrm{DC}$ component $=1.697496 \mathrm{E}-03 ; \mathrm{THD}=2.240344 \mathrm{E}+00$ per cent

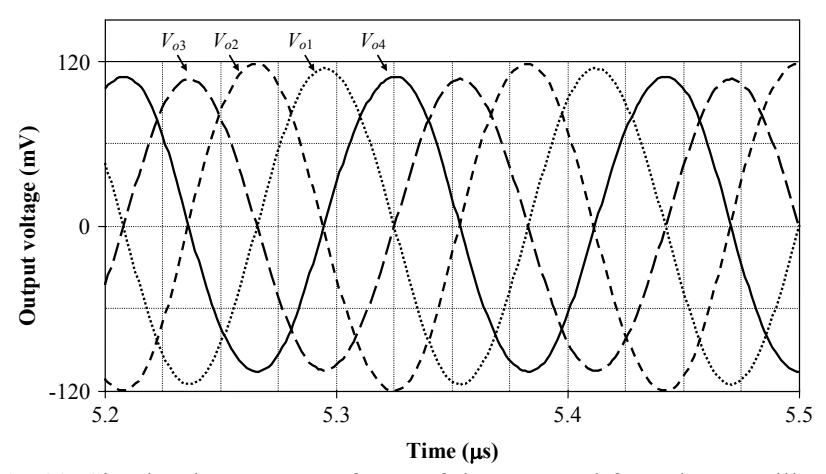

Fig. 22. Simulated output waveforms of the proposed four-phase oscillator in Fig. 20

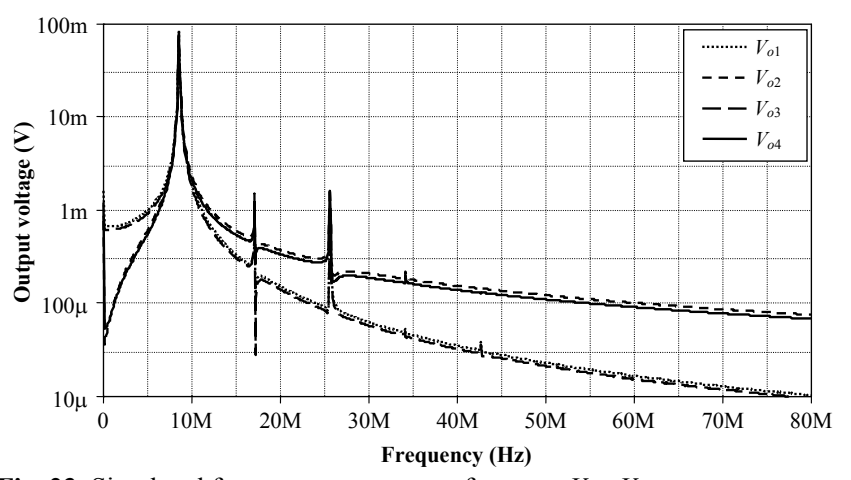

Fig. 23. Simulated frequency spectrums of outputs $V_{o 1}-V_{o 4}$

\section{Conclusions}

This paper presents a new active element from the group of 'voltage differencing' devices, namely voltage differencing inverting buffered amplifier (VDIBA). The input part of the VDIBA is formed by the OTA, which is followed by the IVB with a gain of -1 that makes the introduced element attractive for resistorless and electronically controllable linear circuit design. As an application examples a new resistorless dual-output VM first-order all-pass filter, dual-output second-order all-pass filter, and four-phase quadrature oscillator circuits are proposed. SPICE simulation and experimental results confirm the feasibility of the proposed circuits.

\section{Appendix}

This section provides full nomenclature of the mentioned ABBs in Table 1 in alphabetical order.

C-(I)CDBA: Current-controlled (inverting) current differencing buffered amplifier 


\begin{tabular}{|c|c|}
\hline CCCDTA: & $\begin{array}{l}\text { Current controlled current } \\
\text { differencing } \\
\text { amplifier }\end{array}$ \\
\hline $\mathrm{CCCII}+(-)$ & $\begin{array}{l}\text { Plus-type (minus-type) second- } \\
\text { generation current-controlled } \\
\text { current conveyor }\end{array}$ \\
\hline CC-VCIII-: & $\begin{array}{l}\text { Minus-type current-controlled } \\
\text { third-generation } \\
\text { conveyor }\end{array}$ \\
\hline DDCC: & $\begin{array}{l}\text { Differential difference current } \\
\text { conveyor }\end{array}$ \\
\hline $\mathrm{DVCC}+(-)$ : & (minus-type) \\
\hline & $\begin{array}{l}\text { differential voltage } \quad \text { current } \\
\text { conveyor }\end{array}$ \\
\hline DV-VB: & $\begin{array}{l}\text { Differential-voltage } \\
\text { buffer }\end{array}$ \\
\hline FD-OpAmp: & $\begin{array}{l}\text { Fully-differential operational } \\
\text { amplifier }\end{array}$ \\
\hline IUGA: & Inverting unity gain amplifier \\
\hline IVB: & Inverting voltage buffer \\
\hline MO-CСCCТА: & $\begin{array}{l}\text { Multiple-output current } \\
\text { controlled current conveyor } \\
\text { transconductance amplifier }\end{array}$ \\
\hline OTA: & $\begin{array}{l}\text { Operational transconductance } \\
\text { amplifier }\end{array}$ \\
\hline UGDA: & $\begin{array}{l}\text { Unity gain } \\
\text { amplifier }\end{array}$ \\
\hline UVC: & Universal voltage conveyor \\
\hline VD-DIBA: & $\begin{array}{l}\text { Voltage } \\
\text { differential input } \quad \text { buffered } \\
\text { amplifier }\end{array}$ \\
\hline VDIBA: & $\begin{array}{l}\text { Voltage differencing } \\
\text { buffered amplifier }\end{array}$ \\
\hline
\end{tabular}

\section{Acknowledgment}

The research described in the paper was supported by the following projects: P102/11/P489, P102/10/P561, P102/09/1681, FEKT-S-11-15, and project SIX CZ.1.05/2.1.00/03.0072 from the operational program Research and Development for Innovation.

Authors also wish to thank Prof. Dr. Serdar Ozoguz from the Istanbul Technical University, Turkey, for his discussions made on the proposed circuit and the anonymous reviewers for their useful and constructive comments that helped to improve the paper.

A preliminary version of this paper has been presented at the 7th International Conference on Electrical and Electronics Engineering - ELECO 2011 [29].

\section{References}

[1] S. Maheshwari, "Analogue signal processing applications using a new circuit topology", IET Circuits, Devices Systems, vol. 3, no. 3, pp. 106-115, 2009.

[2] S. Minaei and E. Yuce, "Novel voltage-mode all-pass filter based on using DVCCs", Circuits, Systems, and Signal Processing, vol. 29, no. 3, pp. 391-402, 2010.
[3] S. Maheshwari, "New voltage and current-mode APS using current controlled conveyor", International Journal of Electronics, vol. 91, no. 12 , pp. 735-743, 2004.

[4] S. Minaei and O. Cicekoglu, "A resistorless realization of the firstorder all-pass filter", International Journal of Electronics, vol. 93, no. 3, pp. 177-183, 2006.

[5] P. Kumar, A. U. Keskin, and K. Pal, "Wide-band resistorless allpass sections with single element tuning", International Journal of Electronics, vol. 94, no. 6, pp. 597-604, 2007.

[6] S. Maheshwari, "A canonical voltage-controlled VM-APS with a grounded capacitor", Circuits Systems and Signal Processing", vol. 27, no. 1, pp.123-132, 2008.

[7] B. Metin and K. Pal, "New all-pass filter circuit compensating for C-CDBA non-idealities", Journal of Circuits Systems and Computers, vol. 19, no. 2, pp. 381-391, 2010.

[8] J. Bajer and D. Biolek, "Voltage-mode electronically tunable allpass filter employing $\mathrm{CCCII}+$, one capacitor and differential-input voltage buffer", In Proceedings of the 2010 IEEE 26-th Convention of Electrical and Electronics Engineers in Israel", Eliat, Israel, 2010, pp. 934-937.

[9] B. Metin, K. Pal, and O. Cicekoglu, "CMOS controlled inverting CDBA with a new all-pass filter application", International Journal of Circuit Theory and Applications, vol. 39, no. 4, pp. 417425, 2011.

[10] N. Herencsar, J. Koton, K. Vrba, and B. Metin, "Novel voltage conveyor with electronic tuning and its application to resistorless all-pass filter", In Proceedings of the 2011 34th International Conference on Telecommunications and Signal Processing (TSP), Budapest, Hungary, 2011, pp. 265-268.

[11] V. Biolkova, Z. Kolka, and D. Biolek, "Dual-output all-pass filter employing fully-differential operational amplifier and currentcontrolled current conveyor", In Proceedings of the 7th Int. Conference on Electrical and Electronics Engineering - ELECO 2011, Bursa, Turkey, 2011, pp. 319-323.

[12] A. Toker and S. Ozoguz, "Tunable allpass filter for low voltage operation", Electronics Letters, vol. 39, no. 2, pp. 175-176, 2003.

[13] B. Metin, K. Pal, and O. Cicekoglu, "All-pass filters using DDCCand MOSFET based electronic resistor", International Journal of Circuit Theory and Applications, vol. 39, no. 8, pp. 881-891, 2011.

[14] N. Herencsar, J. Koton, K. Vrba, and S. Minaei, "Electronically tunable MOSFET-C voltage-mode all-pass filter based on universal voltage conveyor", In Proceedings of the International Conference on Computer and Communication Device - ICCCD 2011, Bali Island, Indonesia, 2011, vol. 1, pp. 53-56.

[15] N. Herencsar, J. Koton, J. Jerabek, K. Vrba, and O. Cicekoglu, "Voltage-mode all-pass filters using universal voltage conveyor and MOSFET-based electronic resistors", Radioengineering, vol. 20, no. 1, pp. 10-18, 2011.

[16] S. Minaei and E. Yuce, "High input impedance NMOS-based phase shifter with minimum number of passive elements", Circuits, Systems, and Signal Processing, vol. 31, no. 1, pp. 51-60, 2012.

[17] D. Biolek and V. Biolkova, "First-order voltage-mode all-pass filter employing one active element and one grounded capacitor", Analog Integrated Circuits and Signal Processing, vol. 65, no. 1, pp. 123-129, 2010.

[18] I. A. Khan and M. T. Ahmed, "Electronically tunable first-order OTA-capacitor filter sections", International Journal of Electronics, vol. 61, no. 2, pp. 233-237, 1986.

[19] M. Kumngern, J. Chanwutitum, and K. Dejhan, "Electronically tunable voltage-mode all-pass filter using simple CMOS OTAs", in Proceedings of the 2008 International Symposium on Communications and Information Technologies - ISCIT 2008, Vientiane, Lao PDR, 2008, pp. 1-5.

[20] C. Tanaphatsiri, W. Jaikla, and M. Siripruchyanun, "An electronically controllable voltage-mode first-order all-pass filter using only single CCCDTA", In Proceedings of the 2008 International Symposium on Communications and Information Technologies - ISCIT 2008, Vientiane, Lao PDR, 2008, pp. 305309.

[21] N. Herencsar, J. Koton, and K. Vrba, "A new electronically tunable voltage-mode active-C phase shifter using UVC and OTA", IEICE Electronics Express, vol. 6, no. 17, pp. 1212-1218, 2009.

[22] N. Pandey, P. Arora, S. Kapur, and S. Malhotra, "First order voltage mode MO-CCCCTA based all pass filter", In Proceedings of the 2011 International Conference on Communications and Signal Processing - ICCSP 2011, Kerala, India, 2011, pp. 535-537.

[23] A. U. Keskin, K. Pal, and E. Hancioglu, "Resistorless first order all-pass filter with electronic tuning", AEU - International Journal of Electronics and Communications, vol. 62, no. 4, pp. 304-306, 2008. 
[24] A. Fabre, O. Saaid, F. Wiest, and C. Boucheron, "High frequency applications based on a new current controlled conveyor", IEEE Transactions on Circuits Systems-I, vol. 43, no. 2, pp. 82-91, 1996

[25] R. L. Geiger and E. Sanchez-Sinencio, "Active filter design using operational transconductance amplifiers: a tutorial", IEEE Circuits Devices Magazine, vol. 1, pp. 20-32, 1985.

[26] D. Biolek, R. Senani, V. Biolkova, and Z. Kolka, "Active elements for analog signal processing: classification, review, and new proposals", Radioengineering, vol. 17, no. 4, pp. 15-32, 2008.

[27] Datasheet OPA860 - Wide Bandwidth Operational Transconductance Amplifier (OTA) and Buffer. Texas Instruments, SBOS331C-June 2005-Rev. August 2008.

[28] S. Maheshwari, J. Mohan, and D. S. Chauhan, "Novel cascadable all-pass/notch filters using a single FDCCII and grounded capacitors", Circuits, Systems, and Signal Processing, vol. 30, no. 3, pp. 643-654, 2011.

[29] N. Herencsar, J. Koton, S. Minaei, E. Yuce, and K. Vrba, "Novel resistorless dual-output VM all-pass filter employing VDIBA", In Proceedings of the 7th International Conference on Electrical and Electronics Engineering - ELECO 2011, Bursa, Turkey, 2011, pp. 72-74.

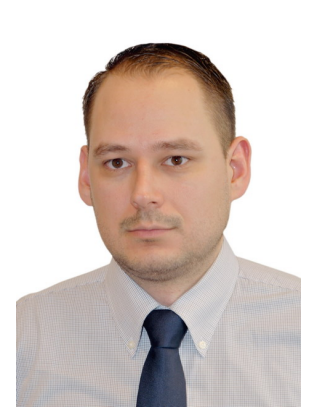

Norbert Herencsar was born in the Slovak Republic in 1982. He received the M.Sc. and Ph.D. degrees in Electronics \& Communication and Teleinformatics from Brno University of Technology, Czech Republic, in 2006 and 2010, respectively. Currently, he is an Assistant Professor at the Department of Telecommunications, Faculty of Electrical Engineering and Communication, Brno University of Technology, Brno, Czech Republic. From September 2009 through February 2010 he was an Erasmus Exchange Student with the Department of Electrical and Electronic Engineering, Bogazici University, Istanbul, Turkey. His research interests include analog filters, current-, voltage- and mixed-mode circuits, electronic circuit \& system design, new active elements and their circuit applications, and oscillators. He is an author or co-author of 23 research articles published in SCI-E international journals, 20 articles published in other journals, and 55 papers published in proceedings of international conferences. In 2011, he received Rector Award in the University competition "Top 10 Excelence VUT 2010" for the 9th most productive scientist at the Brno University of Technology, category "Publications". His paper "Novel resistorless dual-output VM all-pass filter employing VDIBA", presented and published at the 7 th International Conference on Electrical Electronics Engineering - ELECO 2011, Bursa, Turkey, received "The best paper award in memory of Prof. Dr. Mustafa Bayram".

Since 2008, Dr. Herencsar serves in the organizing and technical committee of the International Conference on Telecommunications and Signal Processing (TSP). In 2011, he is guest co-editor of TSP 2010 Special Issue on Telecommunications, published in the Telecommunication Systems journal of Springer. In 2011-2013, he is guest co-editor of TSP 2010, TSP 2011, and TSP 2012 Special Issues on Signal Processing, published in the Radioengineering journal. Dr. Herencsar is Senior Member of the IACSIT and Member of the IEEE, IAENG, and ACEEE. He is also Committee Member of the IACSIT Electronics and Electrical Society (EES).

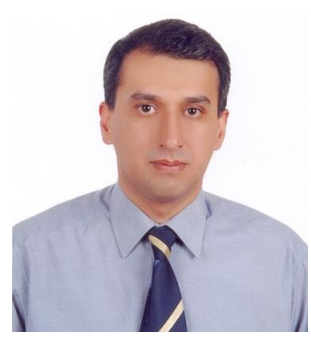

Shahram Minaei received the B.Sc. degree in Electrical and Electronics Engineering from Iran University of Science and Technology, Tehran, Iran, in 1993 and the M.Sc. and Ph.D. degrees in electronics and communication engineering from Istanbul Technical University, Istanbul, Turkey, in 1997 and 2001, respectively. He is currently a Professor in the Department of Electronics and Communication Engineering, Dogus University, Istanbul, Turkey. He has more than 100 publications in scientific journals or conference proceedings. His current field of research concerns current-mode circuits and analog signal processing. Dr. Minaei is a senior member of the IEEE, an associate editor of the Journal of Circuits, Systems and Computers (JCSC), and an area editor of the International Journal of Electronics and Communications (AEÜ).

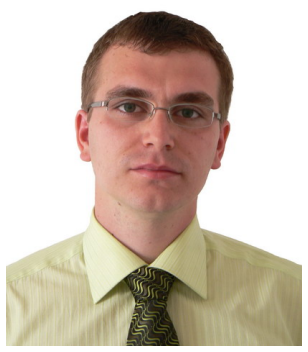

Jaroslav Koton received the M.Sc. an $\mathrm{Ph} . \mathrm{D}$. degree in electrical engineering from the Brno University of Technology (BUT), Brno, Czech Republic, in 2006 and 2009, respectively. He is currently an Assistant Professor at the Dept. of Telecommunications of BUT. His current research is focused on linear- and nonlinear circuit designing methods with current or voltage conveyors, and current active elements. He is an author or co-author of about 85 research articles published in international journals or conference proceedings. Dr. Koton is a Member of IEEE and IACSIT.

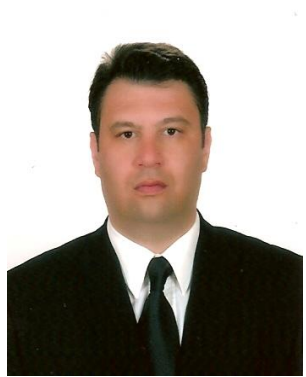

Erkan Yuce was born in 1969 in Nigde, Turkey. He received the B.Sc. degree from Middle East Technical University, the M.Sc. degree from Pamukkale University and the Ph.D. degree from Bogazici University all in Electrical and Electronics Engineering in 1994, 1998 and 2006, respectively. $\mathrm{He}$ is currently an Associative Professor at the Electrical and Electronics Engineering Department of Pamukkale University. His current research interests include analog circuits, active filters, synthetic inductors and CMOS based circuits. He is the author or co-author of about 90 papers published in scientific journals or conference proceedings.

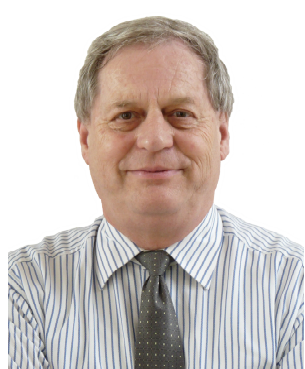

Kamil Vrba received the Ph.D. degree in Electrical Engineering in 1976, and the Prof. degree in 1997, both from the Technical University of Brno. Since 1990 he has been Head of the Dept. of Telecommunications, Faculty of Electrical Engineering and Computer Science, Brno University of Technology, Brno, Czech Republic. His research work is concentrated on problems concerned with accuracy of analog circuits and mutual conversion of analog and digital signals. In cooperation with AMI Semiconductor Czech, Ltd. (now ON Semiconductor Czech Republic, Ltd.) he has developed number of novel active function blocks for analog signal processing such as universal current conveyor (UCC), universal voltage conveyor (UVC), programmable current amplifier (PCA), and others. He is an author or co-author of more than 650 research articles published in international journals or conference proceedings. Professor Vrba is a Member of IEEE, IEICE, and Associate Member of IET. 